\title{
Imaging the reduction of chromium(VI) on magnetite surfaces using in situ electrochemical \\ AFM
}

\author{
Sarah M. Walker ${ }^{\mathrm{a},}{ }^{*}$, Maria C. Marcano ${ }^{\mathrm{a}}$, Will M. Bender ${ }^{\mathrm{a}}$, and Udo \\ Becker $^{\mathrm{a}}$ \\ ${ }^{\mathrm{a}}$ Department of Earth and Environmental Sciences, University of Michigan, 2534 C.C. \\ Little Building, 1100 North University Avenue, Ann Arbor, MI 48109-1005, USA \\ *Corresponding author. Tel.: +1 734-647-5636; fax: +1 734-764-1435; email: \\ smwalk@umich.edu
}

Keywords: Hexavalent chromium, magnetite, redox, atomic force microscopy

\begin{abstract}
Hexavalent chromium is a highly toxic and readily mobile metal contaminant introduced to the environment through a variety of industrial operations. In the presence of reductants, such as Fe(II), and catalytic mineral surfaces, such as iron oxides surfaces, $\mathrm{Cr}$ (VI) may be reduced to a less toxic and relatively insoluble form $\mathrm{Cr}$ (III). In this study, we investigate the interaction between $\mathrm{Cr}(\mathrm{VI})$ and the surface of the $\mathrm{Fe}(\mathrm{II})$-bearing mineral magnetite, $\mathrm{Fe}(\mathrm{II}) \mathrm{Fe}(\mathrm{III})_{2} \mathrm{O}_{4}$, as an example catalyst, using electrochemical atomic force microscopy (EC-AFM). With this method, the redox potential is controlled by an electrode, and $\mathrm{Cr}$ deposition on the magnetite surface is imaged over time as a function of redox potential and $\mathrm{pH}$ of the solution. Quantitative analyses of volumetric growth and surface coverage reveal that more precipitation occurs over time at very negative ($500 \mathrm{mV}$ at $\mathrm{pH} 3,-750 \mathrm{mV}$ at $\mathrm{pH}$, and $-1000 \mathrm{mV}$ at $\mathrm{pH} 11$ ) and very positive $(+1000 \mathrm{mV}$ at $\mathrm{pH} 3$ and $+500 \mathrm{mV}$ at $\mathrm{pH} 11)$ electrochemical potentials. Up to $70 \%$ of the surface is covered with precipitates at $\mathrm{pH} 7$, while less coverage is observed at $\mathrm{pH} 11$ $(<8 \%)$ and $\mathrm{pH} 3(<2 \%)$. Particle growth at $\mathrm{pH} 3$ is predominantly lateral in nature with a tendency to form a higher number of smaller adsorbate particles. At $\mathrm{pH} 11$, growth is primarily vertical (perpendicular to the surface), and smaller particles tend to aggregate into larger clusters on the surface with increasingly negative redox polarization. These
\end{abstract}


33 larger clusters (most likely subcrystalline Cr-(oxy)hydroxides) co-exist with rhombic,

34 crystalline particles that likely have preferred crystallographic growth relationships with

35 the magnetite substrate; the composition of this latter type of particle is most likely

36 chromite, $\mathrm{FeCr}_{2} \mathrm{O}_{4}$, based on the matching crystallography and stability under the $\mathrm{Eh} / \mathrm{pH}$

37 conditions of this experiment.

38 Results from growth analyses were confirmed by batch experiments performed on

39 the same samples used in the AFM, where changes in the Cr concentration in solution

40 were monitored using inductively coupled plasma mass spectrometry (ICP-MS).

41 Virtually all of the $\mathrm{Cr}$ was removed after 30 minutes at $\mathrm{pH} 7$ (starting at $2 \mu \mathrm{M} \mathrm{Cr}(\mathrm{VI})$ ) at

42 all potentials, $\sim 60 \%$ at $\mathrm{pH} 3$, and very little removal at $\mathrm{pH} 11$. X-ray photoelectron

43 spectroscopy (XPS) analyses of the magnetite surface at $\mathrm{pH} 3$ suggest that only $\mathrm{Cr}$ (III)

44 phases are present and that $\mathrm{Cr}$ and/or Fe-Cr oxide phases are more stable at very reducing

45 conditions $(-750 \mathrm{mV}$ ), while $\mathrm{Cr}$ and/or $\mathrm{Fe}-\mathrm{Cr}$ (oxy)hydroxide phases are present under

46 more moderately-reducing conditions $(-250 \mathrm{mV})$. At $\mathrm{pH} 11$, any $\mathrm{Cr}$ deposited is below

47 the detection limit for XPS analysis $(<1 \%$ surface coverage); however, $\mathrm{Fe}(\mathrm{II}) / \mathrm{Fe}$ (III)

48 ratios $(\sim 0.3)$ are lower than the expected ratio of magnetite, which indicates that some

49 oxidation of the surface has occurred. This oxidized layer, possibly maghemite $\left(\gamma-\mathrm{Fe}_{2} \mathrm{O}_{3}\right)$,

50 hematite $\left(\alpha-\mathrm{Fe}_{2} \mathrm{O}_{3}\right)$, or $\mathrm{FeOOH}$, may inhibit the reduction of $\mathrm{Cr}(\mathrm{VI})$ on the surface.

\section{1. Introduction}

52 Chromium, like most transition metals, is redox-active and shows variable 53 geochemical behavior with changes in oxidation state (typically III or VI). Under

54 reducing conditions, $\mathrm{Cr}$ is present as $\mathrm{Cr}$ (III) and occurs naturally as the mineral ore 55 chromite $\left(\mathrm{FeCr}_{2} \mathrm{O}_{4}\right)$. $\mathrm{Cr}(\mathrm{III})$ may also precipitate as $\mathrm{Cr}_{2} \mathrm{O}_{3}$ (eskolaite) or as $\mathrm{Cr}(\mathrm{III})$ 56 hydroxides in aqueous environments at $\mathrm{pH}>3$. The oxidized form of chromium, $\mathrm{Cr}(\mathrm{VI})$, 57 however, is highly carcinogenic and exists primarily as dissolved chromate $\left(\mathrm{CrO}_{4}{ }^{2-}{ }_{(\mathrm{aq})}\right)$, 58 dichromate $\left(\mathrm{Cr}_{2} \mathrm{O}_{7}{ }^{2-}{ }_{\text {(aq) }}\right)$, or as rare chromate solids (e.g., crocoite, $\left.\mathrm{PbCrO}_{4}\right)$. $\mathrm{Cr}(\mathrm{VI})$

59 persists in soils and natural waters indefinitely unless removed through leaching, uptake 60 into the cells of plants and microorganisms, adsorption, or reduction and subsequent 61 precipitation of $\mathrm{Cr}(\mathrm{III})$ phases (Bartlett, 1991). The World Health Organization proposes 
62 a maximum allowable limit of $50 \mu \mathrm{g} \mathrm{L}^{-1}$ (about $1 \mu \mathrm{M}$ ) total chromium in drinking water 63 (WHO, 2011).

64 In the context of environmental contamination, $\mathrm{Cr}(\mathrm{VI})$ poses a significant hazard, 65 while $\mathrm{Cr}(\mathrm{III})$ is relatively benign at low concentrations. Therefore, a detailed 66 understanding of the redox transformations between $\mathrm{Cr}(\mathrm{VI})$ and $\mathrm{Cr}(\mathrm{III})$ has important 67 implications for the chemical sequestration and remediation of chromium. Electron 68 donors available to promote $\mathrm{Cr}$ reduction, e.g., dissolved organic matter or $\mathrm{Fe}(\mathrm{II})_{(\mathrm{aq})}$, are 69 relatively common; however, mineral surfaces are often needed to promote these redox 70 reactions. Atoms at the surfaces of minerals may accept or donate electrons as active 71 participants in the redox reactions, or the mineral surface may serve as a catalyst for the 72 reaction by facilitating electron transfer via an electron shuttle through the surface. 73 Furthermore, mineral surfaces may help lower the activation energy of the overall 74 reaction by providing nucleation or adsorption sites for species in solution (Becker et al., 75 2001; Rosso and Becker, 2003; Tessis et al., 1999; Vorlicek and Helz, 2002). Minerals 76 that are ubiquitous in aqueous environments, including sulfide minerals and $\mathrm{Fe}$ or $\mathrm{Mn}$ 77 oxides/(oxy)hydroxides, play a critical role in surface-mediated reduction (Elsner et al., 78 2004; Hyland and Bancroft, 1990; Taylor et al., 2015). Macroscale kinetic experiments 79 have demonstrated that these redox reactions are often catalyzed by the surfaces of 80 sulfide and oxide minerals, yet the actual nanoscale reaction mechanisms are not 81 understood (Gheju, 2011). Kinetic bottlenecks may include diffusion of chromate 82 towards the mineral surface, dehydration of the chromate and reductant, outer- to inner83 sphere surface complex transitions, and associated angular momentum changes due to 84 electron-spin transfer (Renock and Becker, 2010). In order to clarify these atomic-scale 85 processes, high-resolution microscopy and surface-sensitive analytical techniques are 86 needed.

87 One way to observe the progress of a reduction/precipitation reaction is to study 88 the formation of the reduction product as a function of solution chemistry and redox 89 potential. In this study, atomic force microscopy (AFM) in combination with 90 electrochemical methods (EC-AFM) has been developed and applied to image the 91 reductive precipitation of $\mathrm{Cr}$ on a mineral surface. In our approach, the solution chemistry 
92 (i.e., $\mathrm{pH}, \mathrm{Cr}$ concentration, type and concentration of background electrolyte) is 93 constrained within an experimental cell (although slight modulations in the $\mathrm{pH}$ are 94 inherent to the nature of redox reactions), and the redox potential is controlled by setting 95 the voltage of a potentiostat for a given amount of time. This type of redox-dependent 96 scanning probe microscopy, or electrochemical-SPM (EC-SPM) allows for in situ 97 observations of reactions along a given $\mathrm{Eh} / \mathrm{pH}$ path. Although homogenous reduction of $98 \mathrm{Cr}(\mathrm{VI})$ by $\mathrm{Fe}(\mathrm{II})$ in solution has been observed (Buerge and Hug, 1997; Flury et al., 99 2009), we focus on surface-mediated, heterogeneous reduction, because the experimental 100 conditions can be controlled, and the reaction products can be observed with EC-AFM. 101 EC-SPM has been used relatively rarely for geochemical applications, but this combined 102 method has been a powerful tool in studying processes such as epitaxial mineral growth 103 (Stack et al., 2004b), mineral dissolution morphology and kinetics (Etienne et al., 2004; 104 Higgins and Hamers, 1995; Higgins and Hamers, 1996; Higgins et al., 1996), 105 precipitation (Yuan et al., 2015), adsorption and thin film formation (Stack, 2008; Stack 106 et al., 2004a), and electron transfer (Wigginton et al., 2009).

107 Here, EC-AFM is used to visualize the in situ adsorption/precipitation/reduction 108 of $\mathrm{Cr}(\mathrm{VI})$ onto a magnetite $\left(\mathrm{Fe}_{3} \mathrm{O}_{4}\right)$ surface. Magnetite is a mixed valence iron oxide 109 mineral and is a major constituent of many different types of soil environments (Cornell 110 and Schwertmann, 2006). Additionally, magnetite has been shown to facilitate the 111 heterogeneous reduction of $\mathrm{Cr}(\mathrm{VI})$ to $\mathrm{Cr}(\mathrm{III})$ (Baig et al., 2014; Fendorf et al., 2000; 112 Gheju, 2011; Jung et al., 2007; Kendelewicz et al., 1999; Kendelewicz et al., 2000; 113 Peterson et al., 1996; Peterson et al., 1997). When $\operatorname{Cr}(\mathrm{VI})$ in solution is reduced to $114 \mathrm{Cr}(\mathrm{III})$, there is an associated change in angular momentum when its unpaired spins 115 change from 0 to 3. Magnetite, which has both ferric (five unpaired spins) and ferrous 116 (four unpaired spins) iron, can compensate for this change in angular momentum (each 117 unpaired electron carries an angular momentum of $\hbar / 2$. In order to precisely control the 118 redox potential of the electrochemical cell, the electrode material/substrate of interest has 119 to be adequately conductive to allow for the transfer of electrons from a voltage source to 120 solution (or vice versa). Magnetite is a semiconducting mineral (with a band gap of $1210.1 \mathrm{eV}$ ) and, therefore, well suited as a substrate to study surface-mediated redox 122 reactions. In these experiments, a magnetite sample is loaded into an EC-AFM cell and 
123 polarized at discrete redox potentials in the presence of a $\mathrm{Cr}(\mathrm{VI})$-containing solution.

124 Morphological changes in the magnetite surface and kinetic information are measured in 125 terms of changes in the volume growth of $\mathrm{Cr}$ adsorbates/precipitates, the number of 126 adsorbates/precipitates per unit area, or a combination thereof.

127 The goal is to observe, understand, and quantify $\mathrm{Cr}(\mathrm{VI})$ reduction and 128 adsorption/precipitation onto magnetite at specific Eh and $\mathrm{pH}$ conditions. The Eh and $\mathrm{pH}$ 129 are set by the applied electrochemical potential and the initial acid/base content in 130 solution, respectively, and the progress of the reaction is monitored by imaging the 131 magnetite surface over time. Redox equilibrium diagrams are useful for evaluating which 132 species is predominant over a range of $\mathrm{pH}$ and Eh conditions and what process is being 133 observed (Fig. 1); however, many redox reactions are very slow, and disequilibrium may 134 occur when multiple redox couples are present. As a result of this, a reduction (or 135 oxidation) process may be observed at a redox potential that is actually lower (higher) 136 than expected from applying equilibrium conditions. In addition, it is possible that the 137 dominant species predicted by the Nernst equation is less redox-active than other species 138 or even redox-inactive. By measuring precipitation over time, we can compare the growth 139 features that appear at the time scale of these experiments (i.e., minutes to hours) with the 140 species predicted at thermodynamic equilibrium. We can also observe the morphology of 141 adsorbates or precipitates on the surface and see how it changes over time.

142 As a second, more methodological goal, the suitability of EC-AFM is evaluated to 143 capture the kinetics of precipitation as a function of $\mathrm{Eh} / \mathrm{pH}$. This relatively new and 144 underutilized approach is a way to specifically control Eh and $\mathrm{pH}$ and simultaneously 145 look at growth and morphology changes in situ and in almost real time (depending on the 146 time needed to acquire an image). This is a potentially powerful tool to study 147 geochemically relevant redox processes. This morphologic information is complemented 148 with surface-sensitive spectroscopy (XPS and AES) in order to determine the 149 composition of $\mathrm{Cr}$ precipitates and analysis of the solution to measure the amount of $\mathrm{Cr}$ 150 removed. This knowledge will help develop a mechanistic model for surface-mediated 151 reductive precipitation of Cr. 


\section{Methods}

\subsection{Electrochemical AFM experiments}

The magnetite samples used in this study are octahedral-dodecahedral crystals collected from Mineville, New York and the Itabira District, Minas Gerais, Brazil (Ward's Science, USA). Minor amounts of titanium and aluminum were measured with energy-dispersive x-ray spectroscopy (EDS). The crystals were cut using a water-saw parallel to triangular (111) growth faces. The chosen faces were largely free of inclusions. The large octahedral magnetite crystals from the Itabira District are associated with minor occurrences of high-grade hematite bodies in this iron-rich district, and impurities are generally minor. The samples were polished with silicon carbide paper (grit sizes 180, 400, 600, 800, 2400, and 4000) and $0.3 \mu \mathrm{m}$ and $0.05 \mu \mathrm{m}$ alumina powders in sequence. Samples were then sonicated for 10 minutes and rinsed with ethanol and acetone in order to remove any contaminants introduced through polishing. Samples were polished and rinsed immediately prior to EC-AFM experiments in order to expose a "fresh" surface and minimize oxidation of $\mathrm{Fe}(\mathrm{II})$ to $\mathrm{Fe}(\mathrm{III})$ on the surface. The exposed areas of the final samples were approximately $15 \mathrm{~mm}^{2}$ to $18 \mathrm{~mm}^{2}$.

Our experimental setup consists of a three-electrode configuration in which magnetite serves as the working electrode, a platinum wire is the counter electrode, and a silver wire is the quasi-reference electrode $(+250 \mathrm{mV} v s$. the standard hydrogen electrode, SHE). In this electrochemical cell (Appendix A Fig. A1. Bruker Corporation, Santa Barbara, California), the magnetite samples were affixed flat on an etched Teflon ${ }^{\circledR}$ disk using Torr Seal ${ }^{\circledR}$ low vapor pressure epoxy. The Teflon disk was then mounted to the base of the AFM fluid cell, and electrical contact was established with a spring through a small opening in the disk. The redox potential was controlled using a CHI 760D potentiostat, and EC-AFM experiments were performed using an in-house Dimension Icon atomic force microscope (Bruker). Electrolyte solutions were prepared using ultrapure water (i.e., Milli-Q ${ }^{\circledR}$ water, typically $18.2 \mathrm{M} \Omega \mathrm{cm}$ at $25{ }^{\circ} \mathrm{C}$ ) and reagent-grade $\mathrm{Na}_{2} \mathrm{Cr}_{2} \mathrm{O}_{7} \cdot 2 \mathrm{H}_{2} \mathrm{O}$ and $\mathrm{KCl}$. The $\mathrm{pH}$ was adjusted using $0.01 \mathrm{M} \mathrm{HCl}$ and $0.1 \mathrm{M} \mathrm{NaOH}$. For all experiments, the initial $\mathrm{pH}$ of the electrolyte solutions was approximately 3, 7, or 11; these values were chosen in order to capture a broad range of possible $\mathrm{pH}$ conditions. 
182 Previous studies have shown that magnetite can reduce $\mathrm{Cr}(\mathrm{VI})$ in solution at neutral $\mathrm{pH}$, 183 although less evidence exists at more extreme $\mathrm{pH}$ values (Peterson et al., 1996; Peterson 184 et al., 1997). Due to the relatively small volume of the experimental cell $(2 \mathrm{~mL})$, the 185 decision was made not to use a buffering agent in order to avoid possible complexation of 186 Cr by the buffering agent in solution or competition for surface sites on the magnetite 187 (Sibanda and Young, 1986; Sokołowska and Bal, 2005; Welch et al., 2002). Still, in order 188 to consider the potential $\mathrm{pH}$ change, we estimate the upper limit of $\mathrm{pH}$ change as a 189 function of hydronium consumption described in Eqns. 1a and 1b.

$$
\begin{aligned}
& 2 \mathrm{CrO}_{4}{ }^{2-}{ }_{(\text {aq })}+6 \mathrm{e}^{-}+10 \mathrm{H}^{+} \rightarrow \mathrm{Cr}_{2} \mathrm{O}_{3(\mathrm{~s})}+5 \mathrm{H}_{2} \mathrm{O} \\
& 2 \mathrm{CrO}_{4}{ }^{2-}{ }_{(\mathrm{aq})}+6 \mathrm{e}^{-}+10 \mathrm{H}_{2} \mathrm{O} \rightarrow \mathrm{Cr}_{2} \mathrm{O}_{3(\mathrm{~s})}+5 \mathrm{H}_{2} \mathrm{O}+10 \mathrm{OH}^{-}{ }_{(\mathrm{aq})}
\end{aligned}
$$

In the extreme case in which all the $\mathrm{Cr}$ in solution is reduced and none of the $\mathrm{pH}$ change is buffered by either the mineral surface or solution constituents, and by applying this estimate to the least $\mathrm{pH}$ buffered solution of $\mathrm{pH} 7,10^{-5} \mathrm{M}$ hydroxide ions would be produced (or an equal amount of hydronium consumed) in a $2 \mu \mathrm{M}$ chromate solution. This would result in a maximum $\mathrm{pH}$ change of +2 units from $\mathrm{pH} 7$ to 9 . This effect would be negligible at $\mathrm{pH} 3$ (3 to 3.004) or $\mathrm{pH} 11$ (11 to 11.004). Geochemical modeling reveals that the phases expected to dominate at $\mathrm{pH} 7$ are present over several $\mathrm{pH}$ units in either direction, and a change in $\mathrm{pH}$ from 7 to 9 would not greatly affect $\mathrm{Cr}$ speciation in this case, but would somewhat shift the equilibrium away from $\mathrm{Cr}_{2} \mathrm{O}_{3}$ towards dissolved chromate for oxidizing conditions (Fig. 1). Solutions were kept in opaque bottles and refrigerated at $4{ }^{\circ} \mathrm{C}$ to minimize the possibility of photochemical redox reactions (Kleber and Helz, 1992).

Contact mode and Peak Force Tapping (PFT) mode experiments were performed in fluid $\left(1 \mu \mathrm{M} \mathrm{Na} \mathrm{Cr}_{2} \mathrm{O}_{7} \cdot 2 \mathrm{H}_{2} \mathrm{O}\right.$ and $0.01 \mathrm{M} \mathrm{KCl}$ solution) using silicon nitride (DNP, nom. freq. $23 \mathrm{kHz}$, nom. spring constant $0.12 \mathrm{~N} / \mathrm{m}$ ) and silicon tips (ScanAsyst-Fluid+, nom. freq. $150 \mathrm{kHz}$, nom. spring constant $0.7 \mathrm{~N} / \mathrm{m}$ ). In PFT, developed by Bruker, the tip makes intermittent contact with the sample surface, but unlike regular tapping mode, the oscillation of the cantilever is kept at frequencies well below its resonance. This removes artifacts attributed to the dynamics of a resonating system. A linear scan rate of about 1.2 Hz was used with a resolution of 320 samples per line. For each experiment, the open 
212 circuit potential, usually between 0 and $-100 \mathrm{mV}$, was measured and allowed to stabilize

213 for 400 seconds before beginning polarization of the magnetite electrode. Images were

214 later cleaned and flattened using the NanoScope Analysis ${ }^{\circledR}$ software version 1.4 (Bruker

215 Corp). After polarization, the experiment was stopped, and the Cr-electrolyte was

216 removed from the cell and stored for subsequent ICP-MS analysis. The magnetite

217 electrodes were then gently dried with compressed air, and immediately transferred into a

218 controlled atmosphere Coy ${ }^{\circledR}$ vinyl glove box, where they continued to dry for at least 24

219 hours before XPS and AES analysis. The gas in the box was primarily $\mathrm{N}_{2}$ (with $5 \% \mathrm{H}$ ),

220 and $\mathrm{O}_{2}$ levels are $<1 \mathrm{ppm}$ (controlled using a desiccant with a palladium catalyst and an

$221 \mathrm{O}_{2}$ trap, see Taylor et al. (2015) for further details). All experiments were carried out at a

222 temperature of $22 \pm 2{ }^{\circ} \mathrm{C}$. Both types of spectroscopic analyses were performed at the

223 Electron Microbeam Analysis Laboratory at the University of Michigan.

224 A MATLAB script (release 2015a, the MathWorks, Inc., Natwick, Massachusetts,

225 USA) was developed to quantify the precipitates observed on the AFM images. The

226 script first estimates a background for each original grayscale image using a user-defined

227 structural element. This structural element is chosen to distinguish and separate features

228 in the image. The background is then subtracted from the original grayscale image. The

229 intensity values of the corrected grayscale image are mapped to new values, such that $1 \%$

230 of these data are saturated at low and high intensities creating an increased contrast

231 output image. The high-contrast image is then converted to a black and white image

232 based on a threshold value specified by the user. This approach was preferred over 233 standard threshold-finding strategies (e.g., Otsu's method) because choosing a threshold

234 allowed the visual selection of the closest-to-original result (Otsu, 1979). Objects can

235 then be defined, measured, and counted from the binary or black and white representation

236 of the original image. The binary image is a logical array with ones (1) where precipitates

237 exist in the original image and zeros (0) where they do not. To obtain the precipitate

238 heights only, this logical array is multiplied by the image height data exported from the

239 AFM acquisition software. All heights not associated with precipitates are thus discarded.

240 The sum of the heights that correspond to precipitates is finally multiplied by the 241 appropriate area differential to estimate the volume of the precipitates. Importantly, 242 defects on the magnetite surface or interference during the original image acquisition 
243 influence the numbers obtained by this method, which should be taken as estimates

244 instead of precise values. Overall trends and differences are likely to be more relevant in

245 this model than absolute numbers.

\subsection{X-ray photoelectron spectroscopy (XPS)}

249 energies (BE) using a Kratos Axis Ultra XPS with an Al Ka x-ray radiation source

$250(1486.6 \mathrm{eV})$. Before analyses, the samples were degassed overnight in a sample-transfer 251 chamber under a vacuum pressure of $<10^{-5}$ Torr. Analyses were then carried out at a 252 pressure of $<10^{-8}$ Torr. The $\mathrm{x}$-ray emission current and anode voltage used during spectra 253 acquisition were $8 \mathrm{~mA}$ and $14 \mathrm{keV}$, respectively. A charge neutralizer was used during 254 spectra acquisition. Spectra were acquired using a hybrid lens and slot aperture $(700 \times$ $255300 \mu \mathrm{m})$. The analysis area was approximately $2 \mathrm{~mm} \times 1 \mathrm{~mm}$. For survey scans, a pass 256 energy of $160 \mathrm{eV}$ was used with a dwell time of $100 \mathrm{~ms}$ per $1 \mathrm{eV}$ step (10 sweeps). Core 257 scans were performed for the $\mathrm{Cr} 2 \mathrm{p}, \mathrm{Fe} 2 \mathrm{p}, \mathrm{O} 1 \mathrm{~s}$, and $\mathrm{C} 1 \mathrm{~s}$ regions using a $20 \mathrm{eV}$ pass 258 energy and a dwell time of $400 \mathrm{~ms}$ per $0.1 \mathrm{eV}$ step (20-50 sweeps). Spectra were 259 analyzed using the Casa XPS software (version 2.3.16), and binding energies were 260 calibrated to $\mathrm{C} 1 \mathrm{~s}$ at $284.8 \mathrm{eV}$. The signal-to-noise ratio was increased by convolution 261 using a 5-point quadratic polynomial.

\subsection{Auger electron spectroscopy (AES)}

Chemical analyses of the magnetite surfaces were also performed with AES. Measurements were taken using the Physical Electronics Auger Nanoprobe 680. The electron gun with a Schottky thermal field emitter was operated at a beam voltage of $10 \mathrm{keV}$ and current of $10 \mathrm{nA}$. The electron energy analyzer is a full cylindrical mirror analyzer with a capture angle of $42 \pm 6^{\circ}$ for $360^{\circ}$ around the analyzer axis. Samples were held under ultra-high vacuum (ca. $2.0 \cdot 10^{-9}$ Torr) for the duration of analysis. Although magnetite is a semiconducting mineral, some charge from the incident electron beam may accumulate on the surface and cause shifts in electron kinetic energy; therefore, all

271 samples were fixed onto a tilted sample mount $\left(30^{\circ}\right)$ during analysis. Tilting the sample

272 serves to scatter electrons from the incident beam away from the surface so that only a 
273 relatively small number of electrons initiate the Auger process. Spectra were smoothed 274 and differentiated using the MultiPak software package, version 9.6.0 (ULVAC-PHI 275 2014).

276

\subsection{Inductively-coupled plasma mass spectroscopy (ICP-MS)}

Aqueous $\mathrm{Cr}(\mathrm{VI})$ concentrations were measured from the diluted, acidified aliquots of electrolyte using an Agilent 7900 ICP-MS. The quantitative analysis method uses 100 sweeps per reading and the average of three to five replicates per measurement. Interferences were minimized by using a high He flow method in the collision-reaction chamber of the instrument. The analysis was controlled using a simple linear standard calibration curve with 6 points and $\mathrm{Ga}$ as internal standard. Internal standard variation was never above $15 \%$. Analytical precision was better than 7\% RSD based on check standards, laboratory reference material, and sample replicates.

\section{Results and Discussion}

\subsection{Electrochemical AFM}

\subsubsection{Redox processes at $\mathrm{pH} 11$}

The magnetite surface was first imaged in the absence of an applied potential in order to survey the substrate before any induced sorption took place and to test if sorption occurred at the open circuit potential (OCP). With this step, a "background" image is obtained with which to compare growth features that appear on the surface as a function of time and potential (Fig. 2A). Scratches and grooves produced when polishing the magnetite surface serve as reference points during the experiment. The magnetite electrode was then polarized at specific electrochemical potentials $(-250 \mathrm{mV},-750 \mathrm{mV}$, and $+1000 \mathrm{mV}$ ), and the surface was imaged over a period of 20 to 35 minutes at each potential. In all experiments, unless otherwise stated, scanning was briefly paused between images in order to reset the potentiostat and resumed once the redox potential was set to ensure a stable potential during image acquisition. Images were then quantified and analyzed for changes in the number and size of adsorbates and/or precipitates (hereafter collectively referred as sorbates). While these values provide a quantitative measure of sorption over time, the level of uncertainty of the image analysis dictates that 
302 the overall trends and relative differences between potentials (rather than the absolute 303 values) be emphasized.

304 At $-250 \mathrm{mV}$ (vs. SHE), sorbates appear on the surface within the first 10 minutes 305 of polarization. In general, these particles have a diamond-like or rhombic shape with 306 dimensions of approximately $100 \mathrm{~nm} \times 100 \mathrm{~nm}$ and a range in height from $3-17 \mathrm{~nm}$ 307 (average height $6.8 \mathrm{~nm}$, Fig. 2B). The angle between the long axes of these rhombic 308 adsorbates is slightly less than $90^{\circ}\left(78^{\circ}-86^{\circ}\right)$. In a replicate experiment (not shown), the 309 scan angle was rotated by $45^{\circ}$ in order to verify the rhombic particle shape was not an 310 artifact of the AFM tip. Upon changing the scan angle, the pseudo-rhombohedra 311 maintained their original orientation (with respect to stable surface features), which 312 indicates that the observed shape reflects the morphology of the adsorbed particles. Some 313 particles overlap with one another, which may indicate some epitaxial relationship 314 between precipitates. No detectable particle growth was observed during the 35 minutes 315 of polarization. There is also no apparent trend in particle distribution; the particles are 316 distributed evenly on relatively flat regions of the magnetite surface.

317 After approximately 35 minutes of polarization at $-250 \mathrm{mV}$, where only rhombic 318 sorbates were observed, the Eh was set to $-750 \mathrm{mV}$. At this potential, more rhombic 319 features appear on the surface as well as a second class of larger, semi-spheroidal 320 particles. These images are shown and described in further detail in Appendix B, Fig. B2. 321 At this potential, the volume remains relatively constant around $6 \times 10^{7} \mathrm{~nm}^{3}$.

322 In order to oxidize the sorbates deposited on the magnetite under reducing 323 conditions, the magnetite was polarized at $+1000 \mathrm{mV}$ for 30 minutes. Equilibrium 324 thermodynamics does not predict a persistent solid phase over such a wide range of Eh 325 conditions. Therefore, the dissolution/desorption of both the larger semi-spheroidal 326 features and the pseudo-rhombohedra were expected. Both types of particles, however, 327 largely remain on the surface. Furthermore, growth of additional spheres was observed 328 (Fig. 2C). The total sorbate volume is the greatest at the more positive potentials $329(+250 \mathrm{mV}$ and $+500 \mathrm{mV}$, Fig. 3). The number of particles counted on the surface 330 decreases at $+250 \mathrm{mV}$, which indicates that there are fewer, larger particles on the 331 surface, although the percentage of surface coverage remains largely the same after 45 
332 minutes of polarization (between 1 and 7\%). It is possible that both the pseudo333 rhombohedra and the (oblate) spheroids are stable, or at least metastable on the timescale

334 of the experiments, over a range of Eh values, and/or the dissolution kinetics is too slow 335 to observe over the time of the experiment.

336 In order to determine if growth is primarily due to an increase in sorbate height or 337 due to lateral growth, sorbate volume and surface area are compared for the images 338 acquired at $-750 \mathrm{mV}$ and $+500 \mathrm{mV}$ (Fig. 4). The volume increases at a higher rate than 339 the rate of growth for the surface area (scaled for clarity), which indicates that growth is 340 mainly vertical in nature. At $-750 \mathrm{mV}$, the surface coverage remains constant over the 341 duration of the experiment, so the entire volumetric increase may be attributed to vertical 342 growth. The fact that it is more advantageous to grow on top of an existing sorbate 343 indicates an increasing epitaxial mismatch for lateral growth; in other words, it is more 344 energetically favorable to grow new layers on top, rather than making use of the 345 additional bonding partners at a lateral step or kink site (Taylor et al., in rev.). At $346+500 \mathrm{mV}$, both the sorbate volume and area increase, which implies that the particles 347 grow in the vertical and $x$ - and $y$-directions (about $8 \%$ and $21 \%$ each, respectively). The 348 square root of the surface area is also shown in order to compare equal dimensions; this 349 length dimension remains unchanged at $-750 \mathrm{mV}$, yet it increases at a gentle slope at $350+500 \mathrm{mV}$ (21\% increase). To summarize, growth at $\mathrm{pH} 11$ at highly reducing conditions 351 is primarily vertical, while highly oxidizing conditions result in both vertical and lateral 352 sorbate growth. Sorbates that grow under oxidizing conditions are relatively large $353(\sim 0.5-1 \mu \mathrm{m}$ in diameter) and semi-spheroids compared with the rhombi that grow under 354 more mildly reducing conditions. Under reducing conditions, the overall number of 355 islands decreases slightly over time, which may be explained by diffusion and subsequent 356 aggregation of particles on the surface complemented by fast vertical growth.

\subsubsection{Redox processes at $\mathbf{p H} 7$}

358 As with $\mathrm{pH} 11$, a series of AFM images was acquired as a function of time at the 359 redox potentials $0 \mathrm{mV}$ (open circuit potential), $+500 \mathrm{mV},+750 \mathrm{mV}$, and $-500 \mathrm{mV}$ in a 360 solution at a $\mathrm{pH}$ of 7 . At the beginning of the experiment, deposition is observed on the 361 magnetite surface (Fig. 2D). These conditions (redox- and pH-neutral) correspond to the 
362 Eh-pH region where chromite is the dominant $\mathrm{Cr}$ phase; aqueous $\mathrm{Cr}$ (VI) undergoes 363 reductive precipitation in the presence of the magnetite surface and accumulates on the 364 surface as chromite. The texture of the growth features may be described as subhedral; 365 well-defined edges develop on many of the particles and define a roughly rhombic shape. 366 In some cases, two sides form a fan-shaped feature rather than a four-sided 367 rhombohedron. Individual particles, or growth islands, are approximately $75-100 \mathrm{~nm}$ in 368 length, yet these features tend to form larger aggregates. After increasing the potential to $369+500 \mathrm{mV}$, the general appearance of the surface remains largely unchanged, although 370 results from image analyses indicate that there is a 9\% drop in total particle volume in the 371 first 10.5 minutes of polarization followed by a gradual increase from $4.4 \times 10^{6}$ to $3724.6 \times 10^{6} \mathrm{~nm}^{3}$ over the next 10 minutes (Fig. 3).

373 At $+750 \mathrm{mV}$, AFM images show significant rounding of the particles on the 374 surface (Fig. 2E). The original rhombic shape of the precipitates is no longer observed, 375 and the aggregates present at the open circuit potential have decomposed into broader and 376 more gently sloping mounds on the surface. The percentage of the surface covered by 377 growth features increases from approximately $37 \%$ at $+500 \mathrm{mV}$ to $55 \%$ at $+750 \mathrm{mV}$; the 378 volume, however, decreases by $23 \%$ after about 20 minutes of polarization. This trend 379 may be explained by the dissolution of the particles on the surface. The cause of this 380 "rounding" of particles is actually the creation of jagged edges through an increase in the 381 number of kink sites. Kink sites are positions on the surface of a solid that have relatively 382 few bonding partners and are consequently higher in energy. This higher energy state 383 may exist during this experiment due to disequilibrium conditions caused by the rapid 384 changing of the redox potential; however, from an equilibrium energetics point of view, 385 the creation of more energetic kink sites must be compensated by a gain in energy. One 386 possible candidate for this energy gain may be the oxidation and solvation of $\mathrm{Cr}$ : $\mathrm{Cr}(\mathrm{III})$ $387 \rightarrow \mathrm{Cr}(\mathrm{VI}) \mathrm{O}_{4}{ }^{2-}{ }_{(\mathrm{aq})}$. For example, $\mathrm{Cr}(\mathrm{III})$ sorbed onto the surface is oxidized, and the energy 388 gained through the hydration of $\mathrm{Cr}(\mathrm{VI})$ balances out the energy deficit caused by the 389 creation of more kink sites.

390 The final potential in this series of experiments was $-500 \mathrm{mV}$. Polarization during 39121 minutes at this potential resulted in an overall adsorbate volume increase of $9.4 \%$. 392 Most of this growth was observed on one side of the mound features produced at 
$393+750 \mathrm{mV}$ (Fig. 2F). These new growth features are primarily semi-spheroids

394 approximately $30-50 \mathrm{~nm}$ in diameter. The percentage of surface coverage $(\sim 75 \%)$ is

395 higher than that at the more positive potentials, yet does not increase over the duration of

396 the experiment. These conditions plot within the Eh-pH region where $\mathrm{FeCr}_{2} \mathrm{O}_{4}$ is

397 dominant (Fig. 1). These particles are smaller than those that first appear at the OCP. At -

$398500 \mathrm{mV}$, more $\mathrm{Cr}(\mathrm{III})$, as well as Fe(II), is available to form solid compounds.

\subsubsection{Redox processes at $\mathrm{pH} 3$}

400 Volume growth observed during the OCP and at $+250 \mathrm{mV}$ (up to 30 minutes) was

401 minor in comparison to the growth seen at $-500 \mathrm{mV}$ and at $+1000 \mathrm{mV}$ (Fig. 3; Appendix

$402 \mathrm{C}$, Fig. C2). In this set of experiments, the potentiostat was set at $-500 \mathrm{mV}$ during the

403 acquisition of an image (rather than between images), and the results show that

404 deposition occurred almost immediately upon polarization (indicated by the white dashed

405 line in Fig. 2H). In this case, image acquisition is initiated at the OCP, and the

406 polarization is applied part way through the acquisition of the image. This change was

407 made in order to capture growth at time steps shorter than the $\sim 4.5$ minutes per image.

408 After this initial burst of growth, however, the total particle volume decreases before

409 leveling out after 18 minutes. Larger, non-uniform semi-spheroidal particles are first

410 observed on the surface, yet these larger features disappear after 13.5 minutes. Growth is

411 relatively homogeneous over the entire scan area. Lateral vs. vertical growth analysis for

412 images acquired at $-500 \mathrm{mV}$ shows a decrease in the average length and average height

413 in relatively equal proportions (Appendix C, Fig. C2).

414 The positive potentials were also systematically explored at $\mathrm{pH} 3$. The largest 415 amount of volumetric increase occurs at $+1000 \mathrm{mV}$. A representative EC-AFM image is 416 shown in Fig. 2G. The adsorbates appearing for all positive potentials are all semi417 spheroidal and relatively small $(50-100 \mathrm{~nm}$ in diameter, $\sim 25 \mathrm{~nm}$ in height). A lateral $v s$. 418 vertical growth analysis reveals that highly oxidizing conditions $(+1000 \mathrm{mV})$ and low $\mathrm{pH}$ 419 values produces fast lateral growth with a significant increase in growth islands 420 (Appendix C, Fig. C3).

421 Under reducing conditions (i.e., more negative polarization potentials), $\mathrm{Cr}(\mathrm{VI})_{\mathrm{aq}}$ is 422 heterogeneously reduced to the $\mathrm{Cr}(\mathrm{III})$ solids $\mathrm{Cr}_{2} \mathrm{O}_{3}$ or chromite, $\mathrm{FeCr}_{2} \mathrm{O}_{4}$. These phases 
423 are stable at $\mathrm{pH}$ values greater than 3.5. Indeed, sorption is observed at very reducing 424 conditions for all three $\mathrm{pH}$ values $(3,7$, and 11). In this case (i.e., at $\mathrm{pH} 3)$, the initial 425 disequilibrium caused by changing the electrochemical potential may allow for the 426 precipitation of $\mathrm{Cr}-\mathrm{Fe}$ oxides at $\mathrm{pH}$ conditions that are considered to be unstable for these

427 phases. It is also possible that the $\mathrm{pH}$ increased slightly during the reduction reaction to 428 allow for oxide precipitation (Eqn. 1a).

429 At both $\mathrm{pH} 3$ and $\mathrm{pH}$ 11, adsorption/precipitation was highest at very low and 430 very high potentials. At $\mathrm{pH} 7$, maximum growth occurs at $-500 \mathrm{mV}$, and dissolution is 431 observed at $+750 \mathrm{mV}$. While we can rationalize the presence of solid Cr(III) phases as 432 either $\mathrm{Cr}(-\mathrm{Fe})$ oxides or $\mathrm{Cr}(-\mathrm{Fe})$ (oxy)hydroxides under reducing conditions, the 433 precipitation at very positive potentials for $\mathrm{pH} 3$ and 11 is counterintuitive. The Eh-pH 434 model would predict aqueous $\mathrm{HCrO}_{4}^{-}(\mathrm{aq})$ or $\mathrm{CrO}_{4}{ }^{2-}$ as the dominant $\mathrm{Cr}$ phases, yet results 435 from batch chemistry experiments (to be discussed in Section 3.2) show a significant 436 decrease in dissolved $\mathrm{Cr}$ at $\mathrm{pH} 3$ (and not at $\mathrm{pH} 11$ ). We cannot rule out the possibility of $437 \mathrm{Cr}(\mathrm{IV}) \mathrm{O}_{2}$, and another explanation is the precipitation of a ferric iron chromate, $438 \mathrm{Fe}(\mathrm{III})_{3}\left(\mathrm{CrO}_{4}\right)_{2}$. No solubility information was found for this compound; however, $439 \mathrm{Ag}_{2} \mathrm{CrO}_{4}$ and $\mathrm{PbCrO}_{4}$ have very low solubilities $\left(\mathrm{K}_{\mathrm{sp}} \approx 10^{-12}\right.$ and $10^{-13}$, respectively). It is 440 likely, therefore, that $\mathrm{Fe}_{3}\left(\mathrm{CrO}_{4}\right)_{2}$ is also highly insoluble. Although little 441 thermodynamic/solubility information is available for $\mathrm{Fe}_{3}\left(\mathrm{CrO}_{4}\right)_{2}$, its low solubility may 442 allow for precipitation with small amounts of $\mathrm{Cr}$ and $\mathrm{Fe}(\mathrm{III})$ in the system.

\subsection{Batch chemistry analysis}

Since the small area analyzed using EC-AFM may not be representative of $\mathrm{Cr}$ 445 sorption over the entire working electrode surface, these observations were 446 complemented by batch experiments. Changes in the concentration of $\mathrm{Cr}$ in solution were 447 measured at 10-minute intervals over the course of several EC-AFM experiments. At 448 each time interval, the experiment was stopped, and the entire volume of solution was 449 removed and analyzed using ICP-MS. The magnetite electrode was then re-polished 450 before the next experiment. Given the solubility behavior of $\mathrm{Cr}$ (i.e., $\mathrm{Cr}$ (VI) compounds 451 are often several orders of magnitude more soluble than $\mathrm{Cr}$ (III) compounds), we assume 452 that any $\mathrm{Cr}$ removed from solution is $\mathrm{Cr}(\mathrm{III})$ that has precipitated or $\mathrm{Cr}(\mathrm{VI})$ that has 
453 adsorbed onto the magnetite surface; the remaining $\mathrm{Cr}$ is present as an aqueous $\mathrm{Cr}(\mathrm{VI})$ 454 oxyanion, such as $\mathrm{CrO}_{4}{ }^{2-}$ (aq).

455 Results from $\mathrm{pH} 11$ experiments indicate that very little $\mathrm{Cr}$ is removed from 456 solution (Fig. 5). We would expect to see some $\mathrm{Cr}$ removal as either $\mathrm{Cr}_{2} \mathrm{O}_{3}$ or $\mathrm{FeCr}_{2} \mathrm{O}_{4}$ at 457 the more negative potentials. As will be discussed in the next section, oxidation and 458 subsequent passivation of the magnetite surface at $\mathrm{pH} 11$ may explain the lack of $\mathrm{Cr}$ 459 deposition. One point of concern for the analysis is the excursion above the initial $\mathrm{Cr}$ 460 concentration of $2 \mu \mathrm{M}$ at $-1000 \mathrm{mV}$ and $-500 \mathrm{mV}$. The high error registered for these 461 points likely arises from complications associated with the matrix $\mathrm{pH}$ adjustments 462 required for measuring, which have an initial $\mathrm{pH}$ of 11 . The small sample size of the EC 463 cell prevented $\mathrm{pH}$ monitoring during and after the experiment. However, this variance 464 does not invalidate the overall trend that relatively little $\mathrm{Cr}$ is removed from solution at $465 \mathrm{pH} 11$.

466 At $\mathrm{pH} \mathrm{7,} \mathrm{nearly} \mathrm{all} \mathrm{of} \mathrm{the} \mathrm{Cr}$ was removed from solution across all potentials 467 (results not shown). This is consistent with the relatively high percentage of surface 468 coverage measured from the AFM images. Although the total sorbate volume calculated 469 at $\mathrm{pH} 7$ is not as high as the volume calculated at $\mathrm{pH} 3$, more of the surface is covered 470 with sorbates. Extrapolating this observation over the entire electrode surface $\left(\sim 15 \mathrm{~mm}^{2}\right.$ 471 vs. $1 \mu \mathrm{m}^{2}$ for AFM images), it is feasible that all of the initial $\mathrm{Cr}(\mathrm{VI})$ in solution is 472 reduced and precipitates as $\mathrm{Cr}(\mathrm{III})$ on the magnetite.

473 Overall trends of $\mathrm{Cr}$ reduction beyond the error of measurement can be 474 distinguished, particularly for the experiments at $\mathrm{pH}$ 3. At $\mathrm{pH} 3$, similar amounts of $\mathrm{Cr}$ 475 removal from solution are observed at all potentials tested ( $60 \%$ after 30 minutes). 476 Maximum removal occurred at $+1000 \mathrm{mV}$, the most oxidizing potential $(\sim 65 \%)$, while 477 the least $\mathrm{Cr}$ was removed at $+500 \mathrm{mV}(\sim 59 \%)$. At $+500 \mathrm{mV}$, approximately $50 \%$ of the $478 \mathrm{Cr}$ is removed, yet this rate of removal rapidly decreases and eventually levels out after 47930 minutes of reaction. Cr removal at $\mathrm{pH}-500 \mathrm{mV}$, however, is nearly linear over the 480 entire 30-minute period. EC-AFM experiments at this potential result in a rapid increase 481 in initial growth followed by a decrease in the total particle volume before the volume 482 levels out after $\sim 15-18$ minutes of scanning. This surge in growth occurred on a time 
483 scale shorter than the 10-minute interval used for the batch chemistry experiments, and 484 therefore would not be captured by the ICP-MS data. Image analyses are still consistent 485 with a linear decrease in the concentration of $\mathrm{Cr}$ in solution over time.

An attempt was made to measure the possible release of Fe into solution (as an 487 indication of magnetite dissolution), but any $\mathrm{Fe}$ in solution was below the detection limit 488 of the spectrometer, which is on the order of $1 \mathrm{ppb}\left(10^{-9} \mathrm{M}\right)$. White et al. (1994) report 489 magnetite dissolution rates ranging from 0.3 to $13 \times 10^{-14} \mathrm{~mol} \cdot \mathrm{cm}^{-2} \cdot \mathrm{s}^{-1}$ in $\mathrm{pH} 1-7$ anoxic

490 solutions, and these rates decrease with increasing $\mathrm{pH}$. Using these rates to estimate the amount of $\mathrm{Fe}(\mathrm{II})$ released into solution over 30 minutes of polarization, Fe concentrations 492 should be high enough to be detected by instrument (i.e., $10^{-7}$ or $10^{-8} \mathrm{M}$ ). Dissolved $\mathrm{O}_{2}$ 493 present in the experimental solution may re-oxidize some of the Fe(II), so these estimates 494 may be slightly high; however, the absence of measureable Fe in solution suggests that 495 the sorbates present on the magnetite have a mixed Fe-Cr composition. spatially-averaged spectroscopic evidence of $\mathrm{Cr}$ and to measure its oxidation state. This 500 was done for a subset of the same magnetite samples that were previously used for ECAFM experiments, polarized at $-750 \mathrm{mV},-250 \mathrm{mV}(\mathrm{pH} 3$ and $\mathrm{pH} 11)$, and $+1250 \mathrm{mV}$ ( $\mathrm{pH} 11$ only). For the samples prepared at $\mathrm{pH} 3$, binding energies (BE) for $\mathrm{Cr} 2 \mathrm{p}_{3 / 2}$ peaks 503 (calibrated to $\mathrm{C} 1 \mathrm{~s}$ at $284.8 \mathrm{eV}$ ) are consistent with $\mathrm{Cr}$ (III) (main peak components range 504 from 575.4-577.4 eV) (Jung et al., 2007). The chemical shift between Cr(III) and Cr(VI) 505 is relatively large, approximately $2.5 \mathrm{eV}$ for single peak-fitted spectra (Kendelewicz et

506 al., 1999; Kendelewicz et al., 2000; Suzuki et al., 1997), no peaks were observed at this 507 higher binding energy, typically around $579 \mathrm{eV}$. This indicates that $\mathrm{Cr}(\mathrm{VI})$ reduction on 508 the magnetite surface is complete.

509 Multiplet splitting, not to be confused with spin-orbit splitting, can also occur 510 when an atom has unpaired valence electrons, such as $\mathrm{Cr}$ (III) (with the electronic 511 configuration: [Ar] $3 \mathrm{p}^{6} 3 \mathrm{~d}^{3}$, i.e., with three unpaired $\mathrm{d}$ electrons). Upon emission of a 512 core-level electron, these unpaired valence electrons may couple with unpaired core 
513 electrons to create a number of final energy states. This results in a multi-peak envelope 514 rather than a sharp elemental line. In our initial fitting, we assume a single broad 515 component to get a first approximation of the $\mathrm{Cr} 2 \mathrm{p}$ and $\mathrm{O} 1 \mathrm{~s}$ peak positions (Fig. 6). In a 516 more detailed fitting with at least two multiplet components for each peak, the $\mathrm{Cr} 2 \mathrm{p}$ 517 binding energies for the magnetite polarized at the more reducing potential $(-750 \mathrm{mV}, \mathrm{pH}$ 518 3) are slightly lower than those of the magnetite polarized at $-250 \mathrm{mV}$. For clarity, the 519 samples prepared at $-750 \mathrm{mV}$ and $-250 \mathrm{mV}$ will be referred to as sample A and sample 520 B, respectively. For sample A (more reduced), positions of the main peak components are 521575.4 and $576.8 \mathrm{eV}$, compared with 576.1 and $577.3 \mathrm{eV}$ for sample B (less reduced). 522 Additionally, the separation between $2 \mathrm{p}_{3 / 2}$ and $2 \mathrm{p}_{1 / 2}$ for sample $\mathrm{A}$ is more consistent with 523 the peak separation reported for $\mathrm{Cr}_{2} \mathrm{O}_{3}$ and $\mathrm{FeCr}_{2} \mathrm{O}_{4}(9.45 \mathrm{eV}$ reported by Ünveren et al. 524 (2004) compared with $9.2 \mathrm{eV}$ measured in this study). As predicted by geochemical 525 modeling, we observe the formation of $\mathrm{Cr}$ and/or $\mathrm{Fe}-\mathrm{Cr}$ oxide phases on the magnetite 526 surface under very reducing conditions $(-750 \mathrm{mV})$. The $\mathrm{Cr} 2 \mathrm{p}$ spectra for $\mathrm{Cr}_{2} \mathrm{O}_{3}$ and $527 \mathrm{FeCr}_{2} \mathrm{O}_{4}$, however, are nearly identical (Biesinger et al., 2004; Biesinger et al., 2011; Jung 528 et al., 2007), and due to the Fe $2 p$ signal from the magnetite substrate, we were unable to 529 distinguish between these two phases.

530 In comparison, the higher binding energies for chromium phases deposited on 531 sample $\mathrm{B}(-250 \mathrm{mV})$ may be indicative of chromium (oxy)hydroxides $\mathrm{Cr}(\mathrm{OH})_{3}, \mathrm{CrOOH}$, 532 or perhaps an $\mathrm{Fe}-\mathrm{Cr}$ solid solution, $(\mathrm{Fe}, \mathrm{Cr})(\mathrm{OH})_{3}$. The binding energies for $\mathrm{Cr}(\mathrm{III})$ in $533 \mathrm{Cr}(\mathrm{OH})_{3}$ are typically $0.5-0.6 \mathrm{eV}$ higher than those for chromium oxides, and this shift 534 increases with increasing number of OH groups (Harvey and Linton, 1981; Kendelewicz 535 et al., 2000; McCafferty et al., 1988). While this higher binding energy is still contained 536 within the $\mathrm{Cr} 2 \mathrm{p}_{3 / 2}$ envelope for sample $\mathrm{B}$, increased $\mathrm{Cr}-\mathrm{OH}$ content may explain this 537 shift towards the higher binding energy. Another way to evaluate the amount of 538 hydroxylation is to compare $\mathrm{O} 1 \mathrm{~s}$ peaks of experimental vs. unreacted magnetite (Fig. 7).

539 The unreacted magnetite surface features an asymmetric $\mathrm{O}$ 1s peak with three main 540 components. The largest component is attributed to lattice $\mathrm{O}$ atoms in the magnetite 541 structure, while the other two components at lower binding energies are likely final state 542 shake-ups (commonly observed in magnetite XPS spectra) and possible surface 543 contamination (e.g., carbonation, non-stoichiometric $\mathrm{O}$ atoms or even some partial 
544 hydroxylation), respectively (Kendelewicz et al., 2000; Wandelt, 1982; Yamashita and 545 Hayes, 2008). Two of the $\mathrm{O} 1 \mathrm{~s}$ peak components for $\mathrm{Cr}_{2} \mathrm{O}_{3}$ and the polarized sample are 546 very similar; however, there is an additional feature present in the reacted magnetite. This 547 third component provides evidence of hydroxylation of the sample surface and the 548 formation of $\mathrm{Cr}$ (and/or $\mathrm{Cr}-\mathrm{Fe}$ ) (oxy)hydroxide phases. At pH 6 and 8, Kendelewicz et al. 549 (2000) report that this hydroxide layer contains little to no Fe. With the reduction of $550 \mathrm{Cr}(\mathrm{VI})$ to $\mathrm{Cr}(\mathrm{III})$, one would expect to see a corresponding increase in $\mathrm{Fe}(\mathrm{III})$ on the 551 magnetite surface; however, both $\mathrm{pH} 3$ spectra do not show a clear shift in Fe peaks or $552 \mathrm{Fe}(\mathrm{II}) / \mathrm{Fe}(\mathrm{III})$ ratios. This would imply that after 20 minutes of polarization, the surface is 553 not yet saturated with reduced $\mathrm{Cr}$ precipitates, and some $\mathrm{Fe}(\mathrm{II})$ is still available to 554 promote reduction.

555 XPS spectra from samples prepared at $\mathrm{pH} 11$ show no peaks for $\mathrm{Cr}$ in the narrow 556 scan, which indicates that any $\mathrm{Cr}$ deposited on the surface is below the detection limit of 557 the instrument ( $\sim 1 \%$ or greater, Fig. 6 ). It is interesting to note that the $\mathrm{Fe}(\mathrm{II}) / \mathrm{Fe}$ (III) ratio 558 of the $\mathrm{pH} 11$ samples is generally lower than the expected ratio in magnetite (avg. ratio $=$ 5590.33 , rather than the stoichiometrically expected value of 0.50 ). Spectra from the +1250 560 and $-250 \mathrm{mV}$ samples also show $\mathrm{Fe} 2 \mathrm{p}$ satellite peaks that are not present in magnetite, 561 but are attributed to ferric Fe present in minerals such as hematite or maghemite. 562 According to Peterson et al. (1997), this oxidized overlayer may be the formation of 563 maghemite, which passivates the magnetite surface from further $\mathrm{Cr}$ reduction. In that 564 particular study, passivation was observed at more neutral $\mathrm{pH}$ values, but may explain 565 why $\mathrm{Cr}$ is not seen on the surface of the $\mathrm{pH} 11$ samples in our experiments.

566 In summary, $\mathrm{Cr}$ deposited on the magnetite surface at $\mathrm{pH} 3$ is entirely reduced $567 \mathrm{Cr}(\mathrm{III})$. Under very reducing conditions $(-750 \mathrm{mV})$, the $\mathrm{Cr} 2 \mathrm{p}$ peak positions and peak 568 separation suggest that $\mathrm{Cr}$ oxides and/or $\mathrm{Fe}-\mathrm{Cr}$ oxides (such as $\mathrm{Cr}_{2} \mathrm{O}_{3}$ or $\mathrm{FeCr}_{2} \mathrm{O}_{4}$ ) are 569 present, while a shift towards a slightly higher binding energies and evidence of 570 hydroxylation may denote $\mathrm{Cr}$ (oxy)hydroxide phases are more stable and deposited on the 571 surface under less reducing conditions $(-250 \mathrm{mV})$. At $\mathrm{pH} 11$, no $\mathrm{Cr}$ is observed due to 572 partial oxidation and possible passivation of the surface by, e.g., maghemite, which 573 would inhibit reduction or dramatically impede the kinetics of the reaction. 
In an effort to identify the phases observed to grow under oxidizing conditions,

576 AES spectra were collected from samples polarized at highly oxidizing conditions at $\mathrm{pH}$

$5773(+1000 \mathrm{mV}), \mathrm{pH} 7(-500 \mathrm{mV})$, and $\mathrm{pH} 11(+500 \mathrm{mV})$. While there is some indication

578 that $\mathrm{Cr}_{2} \mathrm{O}_{3}$ is present at $\mathrm{pH} 3,+1000 \mathrm{mV}$, this evidence is not conclusive. See Appendix

579 D for further detail.

\section{Conclusions}

In this study, electrochemical and atomic force microscopy methods are combined in order to image the deposition of $\mathrm{Cr}$ on the surface of magnetite at variable Eh and $\mathrm{pH}$ conditions. With this method, reactions that occur over the entire Eh-pH range can be observed in situ and complemented with further analysis of the surface and the solution. In this system, quantitative analysis of the AFM images reveals that more $\mathrm{Cr}$ precipitation occurs at very positive and very negative redox potentials at $\mathrm{pH} 3$ and 11. At $\mathrm{pH} 7$, maximum growth occurs at $-500 \mathrm{mV}$, while the total sorbate volume decreases over time at $+750 \mathrm{mV}$. At $\mathrm{pH} \mathrm{3}$, the growth observed under oxidizing conditions is dominated by rapid lateral growth and the nucleation of new 2D growth islands, while growth at more reducing potentials $(-500 \mathrm{mV})$ occurs as a rapid initial deposition of larger particles that decreased in both height and diameter over the 30 minutes of polarization. At $\mathrm{pH} 11$,

592 vertical growth was the primary growth mechanism at both reducing and oxidizing 593 conditions.

Concurrent batch chemistry experiments (and subsequent ICP-MS analysis) show

595 total $\mathrm{Cr}$ removal from solution at all potentials at $\mathrm{pH} \mathrm{7,} \mathrm{about} 60 \%$ removal of $\mathrm{Cr}$ from 596 solution at all potentials at $\mathrm{pH} 3$, and little $\mathrm{Cr}$ removal at $\mathrm{pH} 11$. These observations are 597 supported by results from XPS analyses of the magnetite surface. At pH 3, $\mathrm{Cr}$ (III) and/or $598 \mathrm{Cr}(\mathrm{III})-\mathrm{Fe}(\mathrm{III})$ oxide phases are present at the surface for samples prepared under highly 599 reducing conditions $(-750 \mathrm{mV})$. At more moderately reducing potentials (e.g., $600-250 \mathrm{mV}$ ), XPS analysis suggests the presence of $\mathrm{Cr}(\mathrm{III})-\mathrm{O}-\mathrm{OH}$ phases deposited on the 601 surface. All Cr present on the magnetite appears to have reduced from $\mathrm{Cr}(\mathrm{VI})$ to $\mathrm{Cr}(\mathrm{III})$, 602 although more definitive phase identification may require $\mathrm{x}$-ray techniques with a higher 603 degree of spatial resolution, such as synchrotron-based x-ray absorption spectroscopy 
604 (XAS). No $\mathrm{Cr}$ was detected on the surface at $\mathrm{pH} 11$, although elevated $\mathrm{Fe}(\mathrm{II}) / \mathrm{Fe}(\mathrm{III})$ and $605 \mathrm{Fe}(\mathrm{III})$ satellite structures indicate that the magnetite surface at $\mathrm{pH} 11$ is slightly oxidized,

606 and this oxidized overlayer may inhibit $\mathrm{Cr}(\mathrm{VI})$ reduction. AES analysis, which is slightly 607 more surface sensitive than XPS, supports the presence of some $\mathrm{Cr}$ on the surface at $\mathrm{pH}$ 608 11; however, interpretations drawn from these spectroscopic analyses suffered due to 609 overlap between the O KLL peaks from the substrate and Cr LMM peaks. The deposition 610 observed at positive potentials may be $\mathrm{Fe}_{3}\left(\mathrm{CrO}_{4}\right)_{2}$, yet more work is needed for 611 confirmation. Angle-dependent XPS or high resolution XAS are possible techniques that 612 would help determine $\mathrm{Fe} / \mathrm{Cr}$ ratios as a function of depth.

613 Through the direct control of the oxidizing and reducing conditions as well as $\mathrm{pH}$, 614 EC-AFM in concert with chemical analysis of the solid and liquid, this method presents a 615 new way to study the effects of $\mathrm{Eh}$ and $\mathrm{pH}$ on the reductive precipitation of $\mathrm{Cr}(\mathrm{VI})$. 616 While Eh-pH diagrams may be a first indication of which phases dominate at certain 617 conditions, we see significant sorption where the stability diagram does not predicted a 618 solid phase. For this system, the extension of thermodynamic databases to include less 619 crystalline $\mathrm{Cr}$ hydroxide phases would provide a better description of sorption processes 620 at a wide range of Eh conditions. With further improvements, this relatively underutilized 621 method may be a helpful tool to study the deposition and dissolution of redox-active 622 metals on semi-conducting mineral surfaces in a broader geochemical context.

\section{Acknowledgements}

624 The authors are grateful for the support from the grant EAR1223976 from the 625 National Science Foundation. We also thank Jerry Li at EMAL (U of M) for his 626 assistance with AES analysis. 


\section{References}

Baig, S.A., Wang, Q., Wang, Z.X., Zhu, J., Lou, Z.M., Sheng, T.T., Xu, X.H., 2014. Hexavalent chromium removal from solutions: surface efficacy and characterizations of three iron containing minerals. CLEAN, 42(10): 1409-1414.

Bartlett, R.J., 1991. Chromium cycling in soils and water: links, gaps, and methods. Environ. Health Perspect. 92: 17-24.

Becker, U., Rosso, K.M., Hochella Jr, M.F., 2001. The proximity effect on semiconducting mineral surfaces: a new aspect of mineral surface reactivity and surface complexation theory? Geochim. Cosmochim. Acta 65(16): 2641-2649.

Biesinger, M., Brown, C., Mycroft, J., Davidson, R., McIntyre, N., 2004. X-ray photoelectron spectroscopy studies of chromium compounds. Surf. Interface Anal. 36(12): 1550-1563.

Biesinger, M.C., Payne, B.P., Grosvenor, A.P., Lau, L.W., Gerson, A.R., Smart, R.S.C., 2011. Resolving surface chemical states in XPS analysis of first row transition metals, oxides and hydroxides: Cr, Mn, Fe, Co and Ni. Appl. Surf. Sci 257(7): 2717-2730.

Buerge, I.J., Hug, S.J., 1997. Kinetics and pH Dependence of Chromium(VI) Reduction by Iron(II). Environ. Sci. Technol. 31(5): 1426-1432.

Cornell, R.M., Schwertmann, U., 2006. The iron oxides: structure, properties, reactions, occurrences and uses. John Wiley \& Sons.

De Yoreo, J.J., Vekilov, P.G., 2003. Principles of crystal nucleation and growth. Reviews in mineralogy and geochemistry, 54(1): 57-93.

Elsner, M., Haderlein, S.B., Kellerhals, T., Luzi, S., Zwank, L., Angst, W., Schwarzenbach, R.P., 2004. Mechanisms and products of surface-mediated reductive dehalogenation of carbon tetrachloride by $\mathrm{Fe}(\mathrm{II})$ on goethite. Environ. Sci. Technol. 38(7): 2058-2066.

Etienne, M., Schulte, A., Mann, S., Jordan, G., Dietzel, L.D., Schuhmann, W., 2004. Constant-distance mode scanning potentiometry. 1. Visualization of calcium carbonate dissolution in aqueous solution. Anal. Chem. 76(13): 3682-3688.

Fendorf, S., Wielinga, B.W., Hansel, C.M., 2000. Chromium transformations in natural environments: The role of biological and abiological processes in chromium(VI) reduction. Int. Geol. Rev. 42(8): 691-701.

Flury, B., Frommer, J., Eggenberger, U., Mäder, U., Nachtegaal, M., Kretzschmar, R., 2009. Assessment of long-term performance and chromate reduction mechanisms in a field scale permeable reactive barrier. Environ. Sci. Technol. 42(8): 691-701.

Gheju, M., 2011. Hexavalent chromium reduction with zero-valent iron (ZVI) in aquatic systems. Water Air Soil Poll, 222(1-4): 103-148.

Harvey, D.T., Linton, R.W., 1981. Chemical characterization of hydrous ferric oxides by X-ray photoelectron spectroscopy. Anal. Chem. 53(11): 1684-1688.

Higgins, S.R., Hamers, R.J., 1995. Spatially-resolved electrochemistry of the lead sulfide (galena) (001) surface by electrochemical scanning tunneling microscopy. Surf. Sci. 324(2-3): 263-281.

Higgins, S.R., Hamers, R.J., 1996. Chemical dissolution of the galena(001) surface observed using electrochemical scanning tunneling microscopy. Geochim. Cosmochim. Acta. 60(16): 3067-3073. 
Higgins, S.R., Hamers, R.J., Banfield, J.F., 1996. In-situ real-time imaging of the surface reactions of metal sulfide minerals with electrochemical STM. Abstr. Pap. Am. Chem. Sci. 211: 70-COLL.

Hyland, M.M., Bancroft, G.M., 1990. Palladium sorption and reduction on sulphide mineral surfaces: An XPS and AES study. Geochim. Cosmochim. Acta. 54(1): 117-130.

Jung, Y., Choi, J., Lee, W., 2007. Spectroscopic investigation of magnetite surface for the reduction of hexavalent chromium. Chemosphere, 68(10): 1968-1975.

Kendelewicz, T., Liu, P., Doyle, C., Brown, G., Nelson, E., Chambers, S., 1999. X-ray absorption and photoemission study of the adsorption of aqueous $\mathrm{Cr}$ (VI) on single crystal hematite and magnetite surfaces. Surf. Sci. 424(2): 219-231.

Kendelewicz, T., Liu, P., Doyle, C.S., Brown Jr, G.E., 2000. Spectroscopic study of the reaction of aqueous $\mathrm{Cr}(\mathrm{VI})$ with Fe3O4 (111) surfaces. Surf. Sci. 469(2-3): 144163.

Kleber, R., Helz, G., 1992. Indirect photoreduction of aqueous chromium (VI). Environ. Sci. Technol., 28: 307-312.

McCafferty, E., Bernett, M.K., Murday, J.S., 1988. An XPS study of passive film formation on iron in chromate solutions. Corros. Sci. 28(6): 559-576.

Otsu, N., 1979. Threshold selection method from gray-level histograms. Ieee Transactions on Systems Man and Cybernetics, 9(1): 62-66.

Peterson, M.L., Brown Jr, G.E., Parks, G.A., 1996. Direct XAFS evidence for heterogeneous redox reaction at the aqueous chromium/magnetite interface. Colliods Surf. A. 107: 77-88.

Peterson, M.L., Brown Jr, G.E., Parks, G.A., Stein, C.L., 1997. Differential redox and sorption of $\mathrm{Cr}$ (III/VI) on natural silicate and oxide minerals: EXAFS and XANES results. Geochim. Cosmochim. Acta. 61(16): 3399-3412.

Rai, D., Eary, L., Zachara, J., 1989. Environmental chemistry of chromium. Sci. Total Environ. 86(1): 15-23.

Rai, D., Sass, B.M., Moore, D.A., 1987. Chromium (III) hydrolysis constants and solubility of chromium (III) hydroxide. Inorg. Chem. 26(3): 345-349.

Renock, D., Becker, U., 2010. A first principles study of the oxidation energetics and kinetics of realgar. Geochim. Cosmochim. Acta. 74(15): 4266-4284.

Riou, A., Bonnin, A., 1978. Structure cristalline de $\mathrm{Fe}_{2}\left(\mathrm{CrO}_{4}\right)_{3}\left(\mathrm{H}_{2} \mathrm{O}\right)_{3}$ alpha. Acta Crystallographica B, 24: 706-709.

Rosso, K.M., Becker, U., 2003. Proximity effects on semiconducting mineral surfaces II:: Distance dependence of indirect interactions. Geochim. Cosmochim. Acta. 67(5): 941-953.

Sibanda, H., Young, S., 1986. Competitive adsorption of humus acids and phosphate on goethite, gibbsite and two tropical soils. J. Soil Sci. 37(2): 197-204.

Sokołowska, M., Bal, W., 2005. Cu(II) complexation by "non-coordinating" N-2hydroxyethylpiperazine- $\mathrm{N}^{\prime}$-2-ethanesulfonic acid (HEPES buffer). J. Inorg. Biochem. 99(8): 1653-1660.

Stack, A.G., 2008. Applications of electrochemical scanning tunneling microscopy to adsorption and thin films in geochemical systems. Abstr. Pap. Am. Chem. Sci. 235. 
Stack, A.G., Eggleston, C.M., Engelhard, M.H., 2004a. Reaction of hydroquinone with hematite I. Study of adsorption by electrochemical-scanning tunneling microscopy and X-ray photoelectron spectroscopy. J. Colloid Interface Sci. 274(2): 433-441.

Stack, A.G., Erni, R., Browning, N.D., Casey, W.H., 2004b. Pyromorphite growth on lead-sulfide surfaces. Environ. Sci. Technol. 38(21): 5529-5534.

Suzuki, S., Oku, M., Waseda, Y., 1997. Changes in the Chemical State and Composition of the Clean Surface of $\mathrm{K}_{2} \mathrm{CrO}_{4}$ and $\mathrm{K}_{2} \mathrm{Cr}_{2} \mathrm{O}_{7}$ due to Air Exposure and Argon Ion Bombardment. Surf. Interface Anal. 25(3): 161--166.

Taylor, S.D., Marcano, M.C., Rosso, K.M., Becker, U., 2015. An experimental and ab initio study on the abiotic reduction of uranyl by ferrous iron. Geochim. Cosmochim. Acta. 156(0): 154-172.

Taylor, S.D., Powell, B.A., Becker, U., in rev. Influence of the goethite $(\alpha-\mathrm{FeOOH})$ surface on the stability of distorted fcc $\mathrm{PuO}_{2}$ and $\mathrm{PuO}_{2-\mathrm{x}}$ phases. Surf. Sci.

Tessis, A.C., Penteado-Fava, A., Pontes-Buarque, M., De Amorim, H.S., Bonapace, J.A., de Souza-Barros, F., Vieyra, A., 1999. Pyrite suspended in artificial sea water catalyzes hydrolysis of adsorbed ATP: enhancing effect of acetate. Orig. Life Evol. Biosph. 29(4): 361-374.

Ünveren, E., Kemnitz, E., Hutton, S., Lippitz, A., Unger, W., 2004. Analysis of highly resolved $\mathrm{x}$ - ray photoelectron $\mathrm{Cr} 2 \mathrm{p}$ spectra obtained with a $\mathrm{Cr}_{2} \mathrm{O}_{3}$ powder sample prepared with adhesive tape. Surf. Iinterface Anal. 36(1): 92-95.

Vorlicek, T.P., Helz, G.R., 2002. Catalysis by mineral surfaces: implications for Mo geochemistry in anoxic environments. Geochim. Cosmochim. Acta. 66(21): 36793692.

Wandelt, K., 1982. Photoemission studies of adsorbed oxygen and oxide layers. Surf. Sci. Rep. 2(1): 1-121.

Welch, K.D., Davis, T.Z., Aust, S.D., 2002. Iron autoxidation and free radical generation: Effects of buffers, ligands, and chelators. Arch. Biochem. Biophys. 397(2): 360369.

White, A.F., Peterson, M.L., Hochella Jr, M.F., 1994. Electrochemistry and dissolution kinetics of magnetite and ilmenite. Geochim. Cosmochim. Acta. 58(8): 18591875.

WHO, 2011. Guidelines for drinking water quality, 4th ed. Geneva: World Heath Organization.

Wigginton, N.S., Rosso, K.M., Stack, A.G., Hochella, M.F., 2009. Long-range electron transfer across cytochrome-hematite (alpha- $\mathrm{Fe}_{2} \mathrm{O}_{3}$ ) interfaces. J. Phys. Chem. C, 113(6): 2096-2103.

Yamashita, T., Hayes, P., 2008. Analysis of XPS spectra of $\mathrm{Fe}^{2+}$ and $\mathrm{Fe}^{3+}$ ions in oxide materials. Appl. Surf. Sci. 254(8): 2441-2449.

Yuan, K., Ilton, E.S., Antonio, M.R., Li, Z.R., Cook, P.J., Becker, U., 2015. Electrochemical and spectroscopic evidence on the one-electron reduction of U(VI) to U(V) on magnetite. Environ. Sci. Technol. 49(10): 6206-6213. 


\section{A.1. Schematic of electrochemical AFM cell}

Figure A1 presents a diagram of the electrochemical AFM cell used in these experiments.

\section{Appendix B}

\section{B.1. Detailed description of image analysis procedure:}

768 that preserves the topography of the surface as a function of the $x$ and $y$ location of the

769 scanned area. Using the MATLAB script described in the Methods section, a user-

770 defined structural element is chosen in order to identify features of interest on the surface

771 and estimate the background, or the part of the image considered to be the magnetite

772 substrate. This structural element is typically a circular disk that distinguishes surface

773 elements; increasing the size of this disk allows for larger elements on the surface to be

774 selected (and vice versa for a smaller disk), and the remainder is characterized as the

775 background. These features are confirmed through visual selection, and the background is

776 subtracted from the original grayscale image. With the background-subtracted image, the

777 contrast is increased so that the selected features on the surface are easier to identify.

778 Figure B1 presents each of these steps in detail, beginning with the original grayscale

779 image (A), the original image minus the background (B), and the enhanced contrast

780 image (with background subtracted) (C). At this step, the enhanced contrast images are 781 converted to a black and white image by another user-defined threshold (D). Based on

782 this black and white image, a binary array is created that indicates where sorbates are 783 present (white) and where they are not (black). The number and size (volume and area) of 784 the sorbates are calculated by combining this binary array with the image height 785 information from the raw AFM data. Each image, normalized by the number of samples 786 per line, represents one data point for each of the volume, area, size, and number of 787 sorbate plots (Fig. 3) Figure B1 also shows a 3D model of the derived background (E), 788 which highlights some of the surface defects and polishing grooves, which may influence 789 the absolute values for the sorbate size and shape calculated with this method. For this 790 reason, it is recommended that overall trends be emphasized more than absolute numbers. 
792 Appendix C

793 C.1. Extended description of redox processes at pH 11

794 
In this section, further description, explanation, and interpretation of EC-AFM

796 images at $\mathrm{pH} 11$ and $\mathrm{pH} 3$ are provided. During negative polarization at $\mathrm{pH} 11$, two types

797 of growth features appear on the magnetite surface: pseudo-rhombohedra and larger,

798 spheroidal particles. Some of the rhombic particles appear to grow on top of and slightly

799 adjacent to one another, such as those outlined in the panels labeled 9 and 22 minutes in

800 Fig. C1. This type of crystallographically directed growth may indicate epitaxial or

801 parallel growth on the surface. Crystal intergrowths are about equal in size, and their

802 offset is approximately one-half of the length of each feature $(50-60 \mathrm{~nm})$. Epitaxial

803 relationships may limit the size of each rhombic sorbate, which would explain the

804 occurrence of more sorbates at more negative potentials instead of continued growth of

805 individual particles. The semi-spheroidal particles are significantly larger than the 806 rhombic; their diameters range from $200-600 \mathrm{~nm}$ with a height on the order of $20 \mathrm{~nm}$.

807 Over time (and particularly after 30 minutes), these semi-spheroidal particles diffuse

808 towards each other to form a central particle with smaller pseudo-spheres on the 809 periphery.

810 The semi-spheroidal particles are significantly larger than the rhombic; their 811 diameters range from 200-600 $\mathrm{nm}$ with a height on the order of $20 \mathrm{~nm}$. Over time (and 812 particularly after 30 minutes), these semi-spheroidal particles diffuse towards each other 813 to form a central particle with smaller pseudo-spheres on the periphery. This growth is 814 shown in the lower panels of Fig. C1. The pseudo-spherical sorbates appear to lack a 815 crystallographic or structural relationship to the magnetite substrate, which suggests they 816 are mostly amorphous unlike the pseudo-rhombohedra. Since there is less of an epitaxial 817 relationship between the semi-spheroidal particles and the magnetite surface, which

818 would result in a crystallographic mismatch at a given size, growth of the semi-spheroidal 819 sorbates is uninhibited. In addition, the fact that the semi-spheroidal features are more 820 prone to surface diffusion indicates that they have a smaller (i.e., less negative) interface

821 energy between the sphere-magnetite interface compared to the rhombohedron-magnetite 822 interface. One candidate for such a phase is poorly crystalline chromium hydroxide (Rai 823 et al., 1989; Rai et al., 1987).

\section{C.2. Extended description of redox processes at $\mathbf{p H} 3$}


Figures C2 and C3 provide lateral vs. vertical growth analyses for polarization at $826-500 \mathrm{mV}$ and $+1000 \mathrm{mV}$. After an initial burst of growth at $-500 \mathrm{mV}$, the total volume 827 decreases, although the number of particles increases from $\sim 70$ to 180 (Fig. C2). The 828 average particle length and average height decrease at approximately the same rate. Such 829 a rapid precipitation event may be due to the disequilibrium cause by the initial 830 polarization at very reducing conditions followed by a slow return to a quasi-steady state. 831 At $+1000 \mathrm{mV}$, there is an increase in volume of total adsorbate of $\sim 30 \%$ within 30 832 minutes (Fig. C3). This increase in volume is solely due to an increase in surface 833 coverage, i.e. lateral growth, as shown by the overlap of the scaled volume and scaled 834 area in Fig. C3. Scaling the square root of the surface area shows that this length 835 dimension slightly increases during the $\sim 30$ minutes of polarization and that the entire 836 volume also increases for the experimental settings used. Such an increase in newly837 formed adsorbates would normally be expected in a highly-supersaturated state that is, 838 according to classical crystal growth theory, dominated by two-dimensional nucleation 839 (De Yoreo and Vekilov, 2003).

$840 \quad$ Appendix D

841 D. 1. Auger electron spectroscopy

At $\mathrm{pH} 3, \mathrm{Cr}$ Auger peaks were observed for features resembling the particles 844 imaged in the AFM (Fig. D1). Cr has five Auger lines, although two of these have very 845 low kinetic energies and are difficult to distinguish above the background. The most 846 significant peaks occur at 490,530 , and $560 \mathrm{eV}$, all of which are LMM transitions, yet 847 we will focus on the $490 \mathrm{eV}$ peak; the $530 \mathrm{eV}$ line is almost entirely overwhelmed by the 848 strong O KLL line, and the $560 \mathrm{eV}$ peak is relatively weak in comparison. While it is 849 common practice to differentiate AES spectra due to the broad shape of many Auger 850 lines, here, we show the undifferentiated spectra in order to emphasize the contrast in 851 shape for this set of peaks. The shapes of Auger peaks are potentially very sensitive to 852 changes in chemistry and atomic arrangement of a given compound, especially if the 853 Auger transition involves valence electrons. This particular energy range includes the $\mathrm{Cr}$

854 LMM peak at $\sim 490 \mathrm{eV}$ and the O KLL peak at $\sim 510 \mathrm{eV}$, both of which involve two 855 valence electrons for each transition. All three spectra closely resemble the spectrum for 
856 magnetite, including two relatively strong energy loss lines on the lower kinetic energy 857 side of the O KLL peak at $510 \mathrm{eV}$. The overlap of the O KLL peak with the Cr LMM 858 peak at $490 \mathrm{mV}$ complicates the identification and interpretation of $\mathrm{Cr}$ peaks; however, 859 the Cr LMM peak from the first analysis spot is asymmetric and has a distinct shoulder 860 on the lower kinetic energy side of the peak. The O KLL peak for spot 1 is also 861 asymmetric with a similar shoulder feature. The O KLL peaks were manually aligned at $862510 \mathrm{eV}$ in order to emphasize peak shape and to correct for surface charging; this shift 863 was less than $1.7 \mathrm{eV}$. The presence of these shoulders can either indicate the presence of 864 multiple bond types (e.g., the main O peak could be attributed to oxygen bonded to Fe or $865 \mathrm{Cr}$, and the shoulder with a lower kinetic energy could be due to $\mathrm{O}$ bonded to $\mathrm{H}$ ) or a 866 different structural environment for that particular element. In an attempt to identify the 867 chemical and oxidation state of $\mathrm{Cr}$ from the spectra collected from the magnetite surfaces, 868 AES spectra were collected from three $\mathrm{Cr}$ reference compounds with $\mathrm{Cr}$ in three different 869 oxidation states: $\mathrm{Cr}^{0}$ (Cr metal), $\mathrm{Cr}^{3+}$ (eskolaite, $\mathrm{Cr}_{2} \mathrm{O}_{3}$ ), and $\mathrm{Cr}^{6+}$ (crocoite, $\mathrm{PbCrO}_{4}$, Fig. 870 D2). Because $\mathrm{Cr}_{2} \mathrm{O}_{3}$ and $\mathrm{PbCrO}_{4}$ are insulating minerals, the beam energy used to collect 871 these spectra was $3 \mathrm{keV}$ in order to reduce the amount of peak shift due to charging, 872 which explains why the O KLL line is closer to $515 \mathrm{eV}$. Beam energy does not affect 873 peak morphology. Assigning oxidation states with AES can be quite challenging due to a 874 high background signature, the broad nature of Auger peaks, and the high potential for 875 peak overlap from Auger transitions involving shallow atomic levels; however, we can 876 say with some certainty that $\mathrm{Cr}^{0}$ is not likely present on this magnetite surface $(\mathrm{pH} 3$, $877+1000 \mathrm{mV}$ ). The shape of the Cr LMM $490 \mathrm{eV}$ peak for $\mathrm{Cr}^{0}$ is sharp and slightly shifted 878 towards higher kinetic energies, which is not consistent with the $\mathrm{Cr}$ measured in the $\mathrm{pH} 3$, $879+1000 \mathrm{mV}$ sample. On the other hand, $\mathrm{Cr}_{2} \mathrm{O}_{3}$ provides an Auger line that is most similar 880 to the Cr LMM peak for the first spot analysis: a strong peak close to $490 \mathrm{eV}$ and a 881 shoulder on the lower kinetic energy side. This comparison provides some evidence that 882 the particle analyzed contains $\mathrm{Cr}(\mathrm{III})$ as in $\mathrm{Cr}_{2} \mathrm{O}_{3}$ or $\mathrm{FeCr}_{2} \mathrm{O}_{4}$. Spots 2 and 3 are identical 883 to the magnetite reference spectrum.

884 At pH 7, AES spectra of the magnetite surface were taken after 30 minutes of 885 polarization at $-500 \mathrm{mV}$ (SEM image of scan area and undifferentiated spectra shown in 886 Fig. D3). In the SEM image, a precipitate is shown in white (labeled 'sorbate') on top of 
887 the darker magnetite substrate. The sorbate material contains some amount of Ti (that 888 was dissolved, as an impurity, out of the magnetite substrate), evident by the Ti LMM 889 transition labeled in the AES spectrum. At $498 \mathrm{eV}$, the energy loss feature produced from 890 the O KLL transition in the magnetite has a distinct shoulder on the higher kinetic energy 891 side of the peak. This shoulder is possibly produced by the overlap with the Cr LMM 892 peak at $\sim 490 \mathrm{eV}$. The AES reference spectrum for chromite is also presented in Fig. D3; 893 however, there is no clear indication that chromite contributes to the $\mathrm{Cr}$ shoulder feature.

894 AES spectra were also collected from the Cr-sorbed magnetite surface prepared at

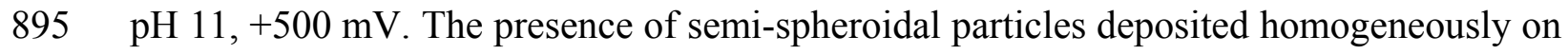
896 the surface distinguishes this sample from the $\mathrm{pH} 3$ and $\mathrm{pH} 7$ samples (Fig. D4). These 897 particles are also present in AFM images acquired under similar oxidizing conditions. 898 The AES spectrum for these particles does contain Cr LMM peaks around $490 \mathrm{eV}$ (as a 899 shoulder) and $530 \mathrm{eV}$ (labeled with arrows in Fig. D5). Unfortunately, these peak 900 positions as well as their morphology are similar to the peaks in both $\mathrm{Cr}_{2} \mathrm{O}_{3}$ and $\mathrm{PbCrO}_{4}$ 901 reference spectra, and the $\mathrm{Cr}$ oxidation state cannot be confidently identified. At $\mathrm{pH} 11$, 902 the magnetite surface is positively charged, and less adsorption of $\mathrm{CrO}_{4}{ }^{2-}$ would occur. If 903 all the $\mathrm{Cr}$ in solution is present as $\mathrm{Cr}(\mathrm{VI})$, it is conceivable that these particles are an $904 \mathrm{Fe}(\mathrm{III})$ chromate phase, e.g., $\mathrm{Fe}_{2}\left(\mathrm{CrO}_{4}\right)_{3} \cdot 3 \mathrm{H}_{2} \mathrm{O}$ (Riou and Bonnin, 1978). 


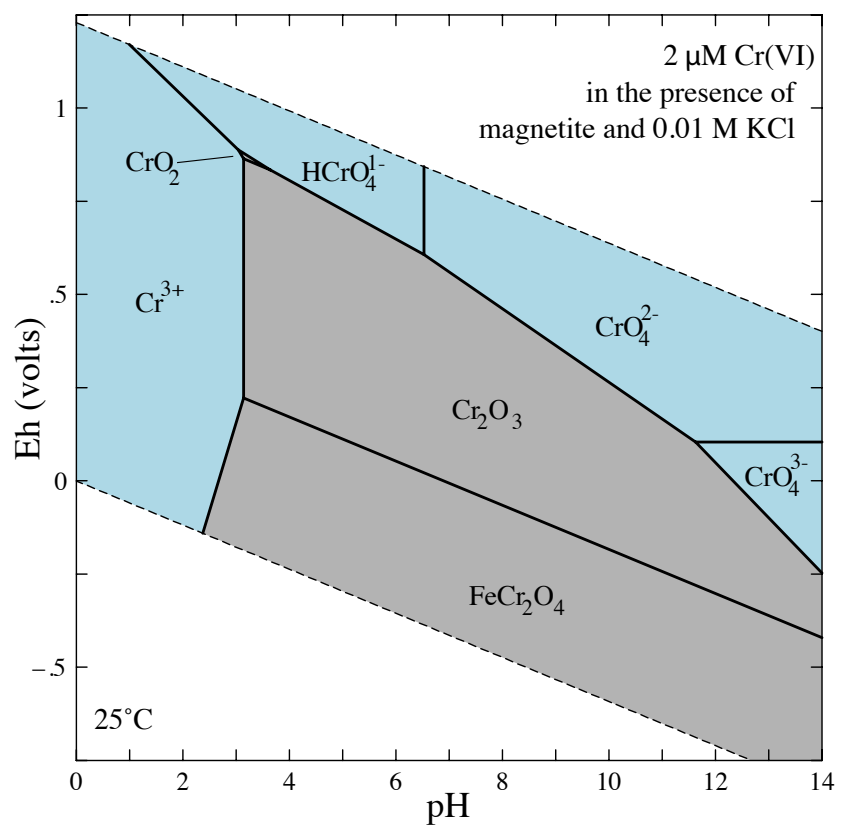

Figure 1 caption: Eh-pH diagram of chromium at the experimental conditions ( $2 \mu \mathrm{M}$ chromate solution). Modeled with Geochemists' Workbench LLNL thermodynamic database. 

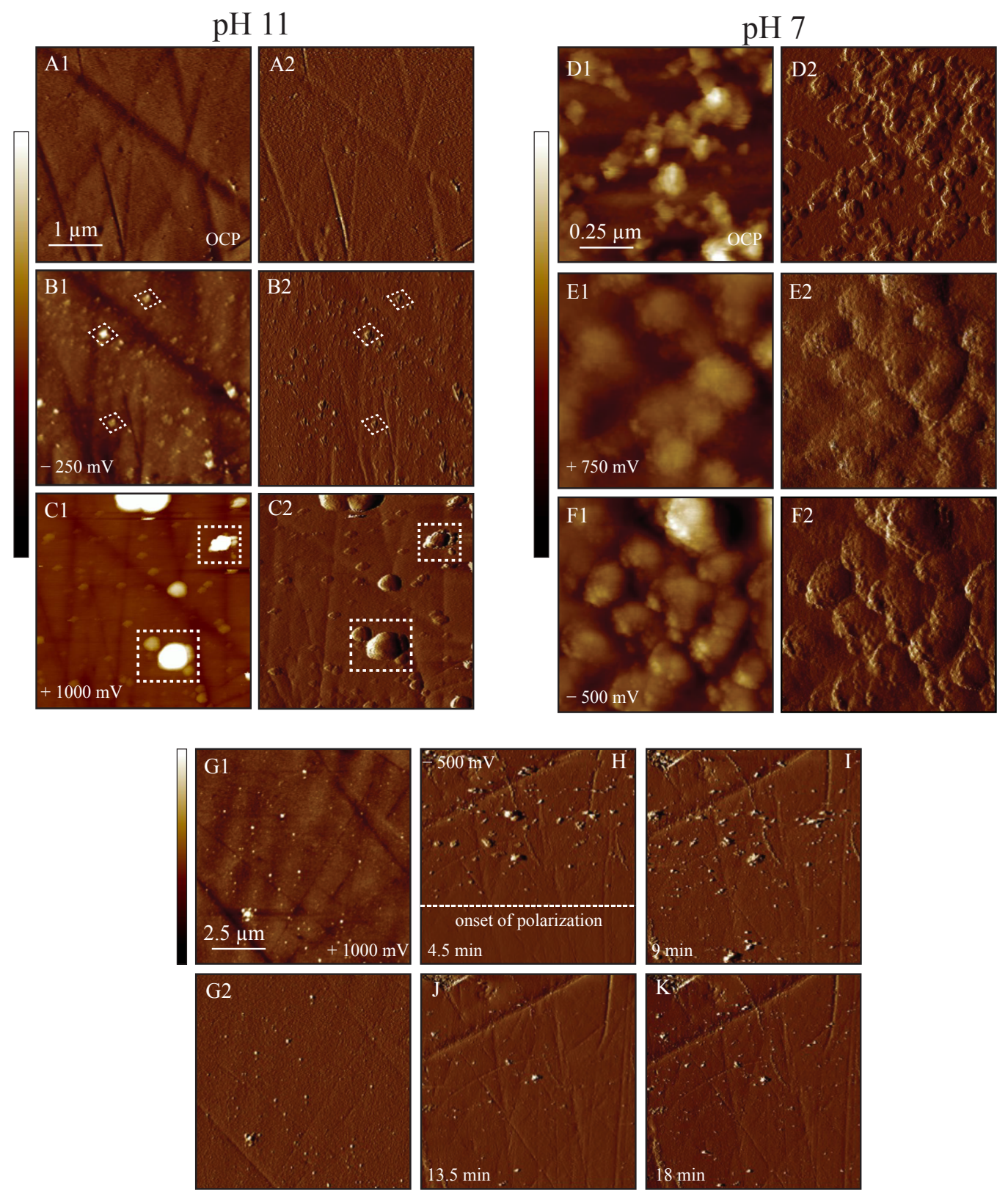

pH 3

Figure 2 caption: Fig. 2. EC-AFM height and Peak Force Error (PFE) images. A-C: pH 11, D-F: pH 7, G$\mathrm{K}: \mathrm{pH}$ 3. A. Color bar: $\pm 18 \mathrm{~nm}$. Open circuit potential (OCP): height (A1), PFE (A2). B. Color bar: \pm $18 \mathrm{~nm}$. Polarization $-250 \mathrm{mV}, 20 \mathrm{~min}$ : height (B1), PFE (B2). White outlines highlight rhombic growth features. C. Color bar: $\pm 50 \mathrm{~nm}$. Polarization $+1000 \mathrm{mV}, 13 \mathrm{~min}$ : height (C1), PFE (C2). White squares indicate new growth at this potential. D. Color bar: $\pm 50 \mathrm{~nm}$. OCP: height (D1), PFE (D2). E. Color bar: \pm $50 \mathrm{~nm}$. Polarization $+750 \mathrm{mV}, 21 \mathrm{~min}$ : height (E1), PFE (E2). F. Color bar: $\pm 50 \mathrm{~nm}$. Polarization $500 \mathrm{mV}, 28 \mathrm{~min}$ : height (F1), PFE (F2). G. Color bar: $\pm 40 \mathrm{~nm}$. Polarization $+1000 \mathrm{mV}, 13.5 \mathrm{~min}$ : height (G1), PFE (G2). (H-K) Color bar: $\pm 40 \mathrm{~nm}$. Polarization $-500 \mathrm{mV}$, PFE, $4.5 \mathrm{~min}(\mathrm{H}), 9 \mathrm{~min}(\mathrm{I}), 13.5 \mathrm{~min}$ $(\mathrm{J}), 18 \mathrm{~min}(\mathrm{~K})$. White dashed line in $(\mathrm{H})$ shows where polarization began. 

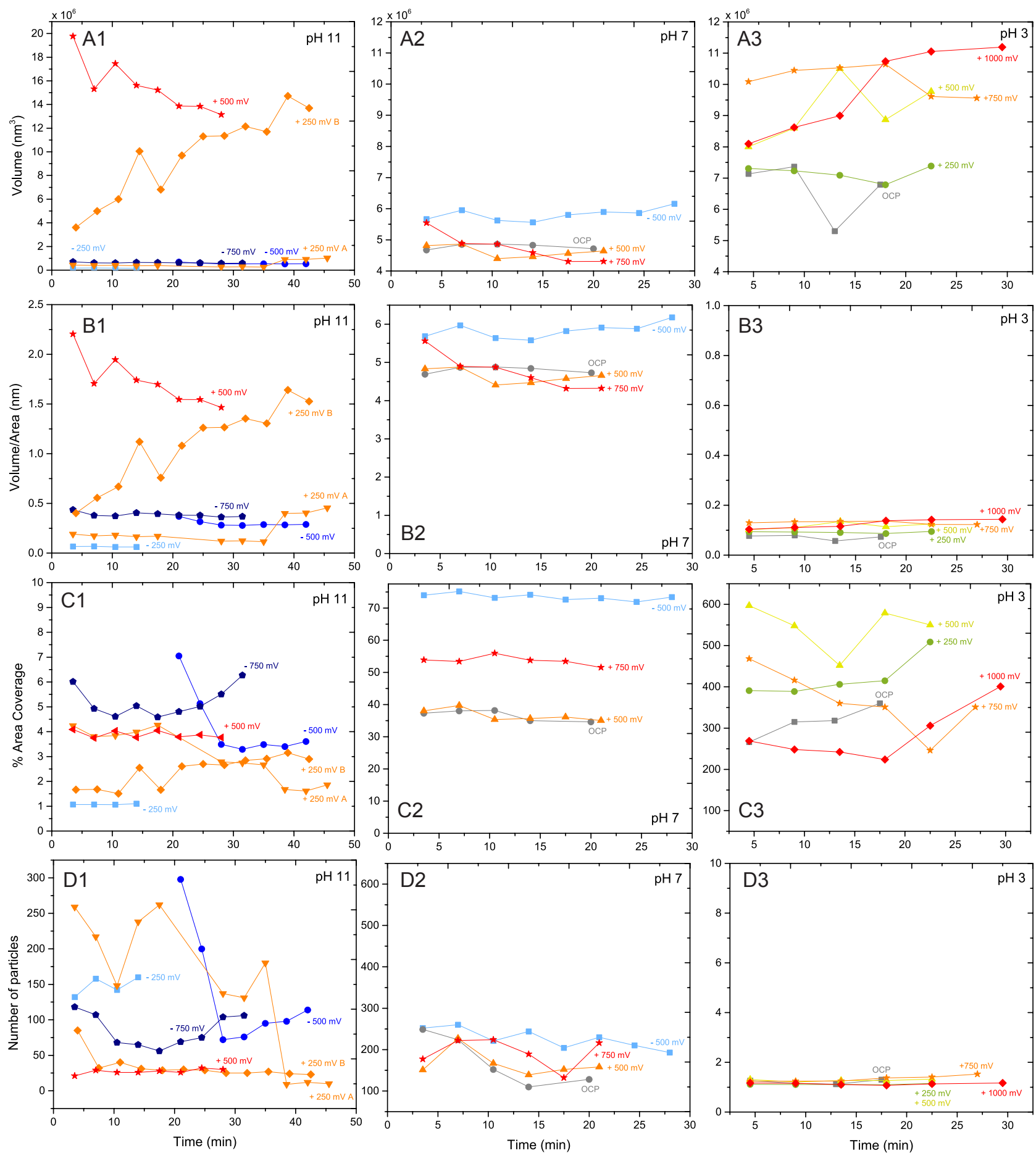

Fig. 3. Sorbate quantification from EC-AFM images at $\mathrm{pH} \mathrm{3,} \mathrm{7,} \mathrm{and} \mathrm{11.} \mathrm{(A)} \mathrm{Total} \mathrm{sorbate} \mathrm{volume.} \mathrm{-}$ $250 \mathrm{mV} \mathrm{A}$ and $-250 \mathrm{mV} \mathrm{B}$ represent two different series of AFM images scanned over different areas of the surface. (B) Volume/sorbate area. (C) Percentage of surface coverage. (D) Number of sorbates plotted over time. 

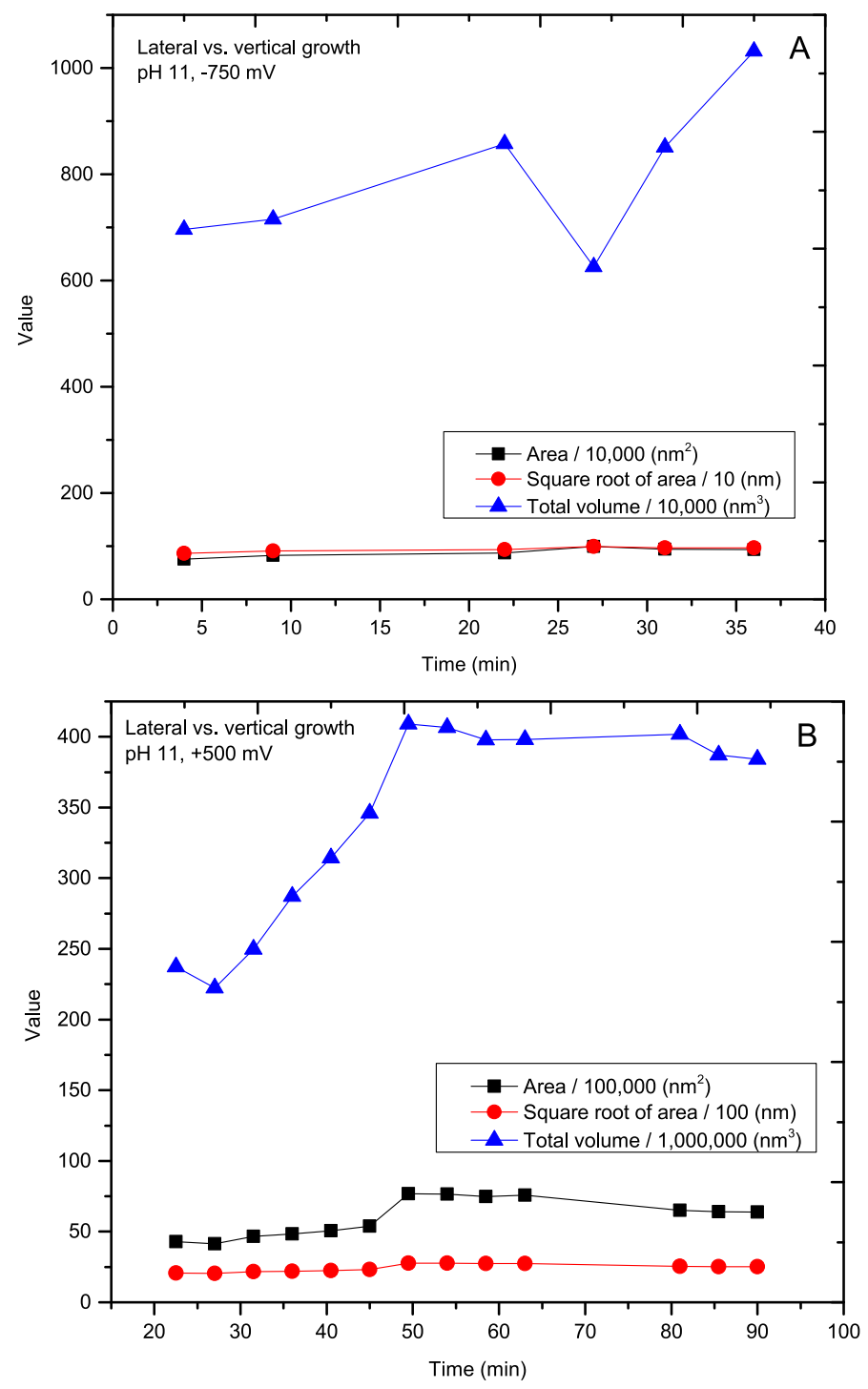

Figure 4 caption: A comparison of volumetric growth dimensions at $\mathrm{pH} 11,-750$ (A) and $+500 \mathrm{mV}$ (B). The total volume and the total area covered by adsorbates (scaled for clarity) are plotted in dark blue and black, respectively. A more rapid increase in total volume versus area implies that growth on the surface is predominantly vertical at $-750 \mathrm{mV}$. Growth at $+500 \mathrm{mV}$ is both lateral and vertical at approximately equal rates, given the $60 \%$ increase in total volume and $48 \%$ increase in area. 

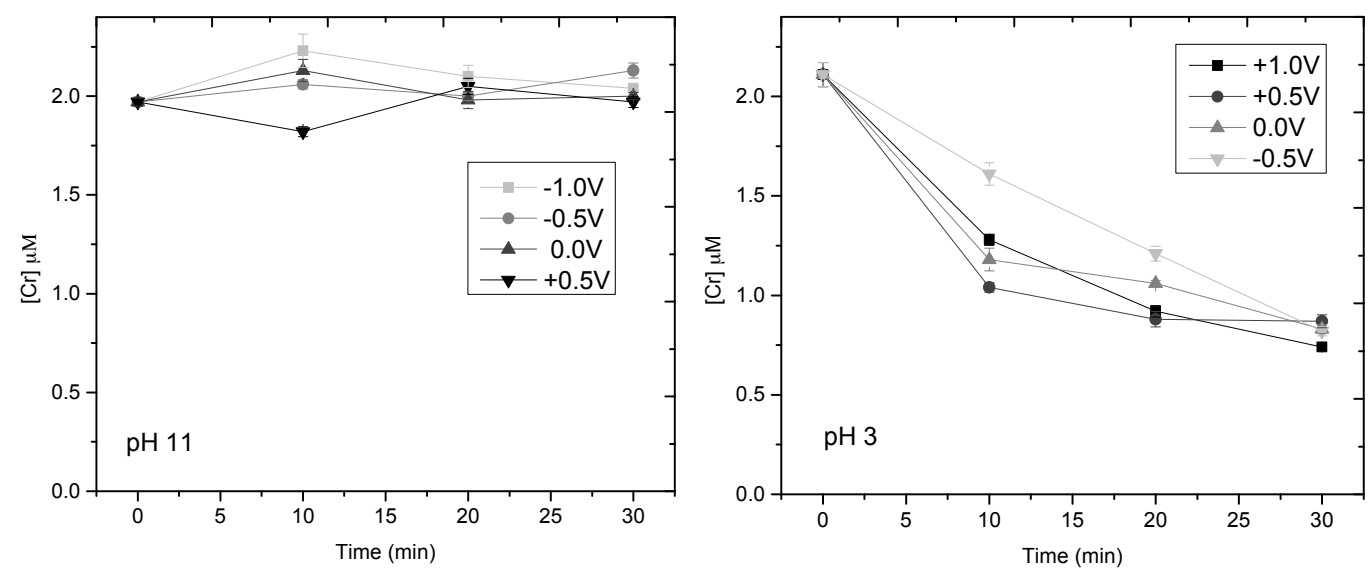

Figure 5 caption: Changes in total dissolved $\mathrm{Cr}$ concentration as a function of time and Eh at $\mathrm{pH} 3$ and 11. Most of the $\mathrm{Cr}$ stays in solution at $\mathrm{pH} 11$. However, at $\mathrm{pH} 3, \mathrm{Cr}$ concentration decreases more at very high and very low potentials. 


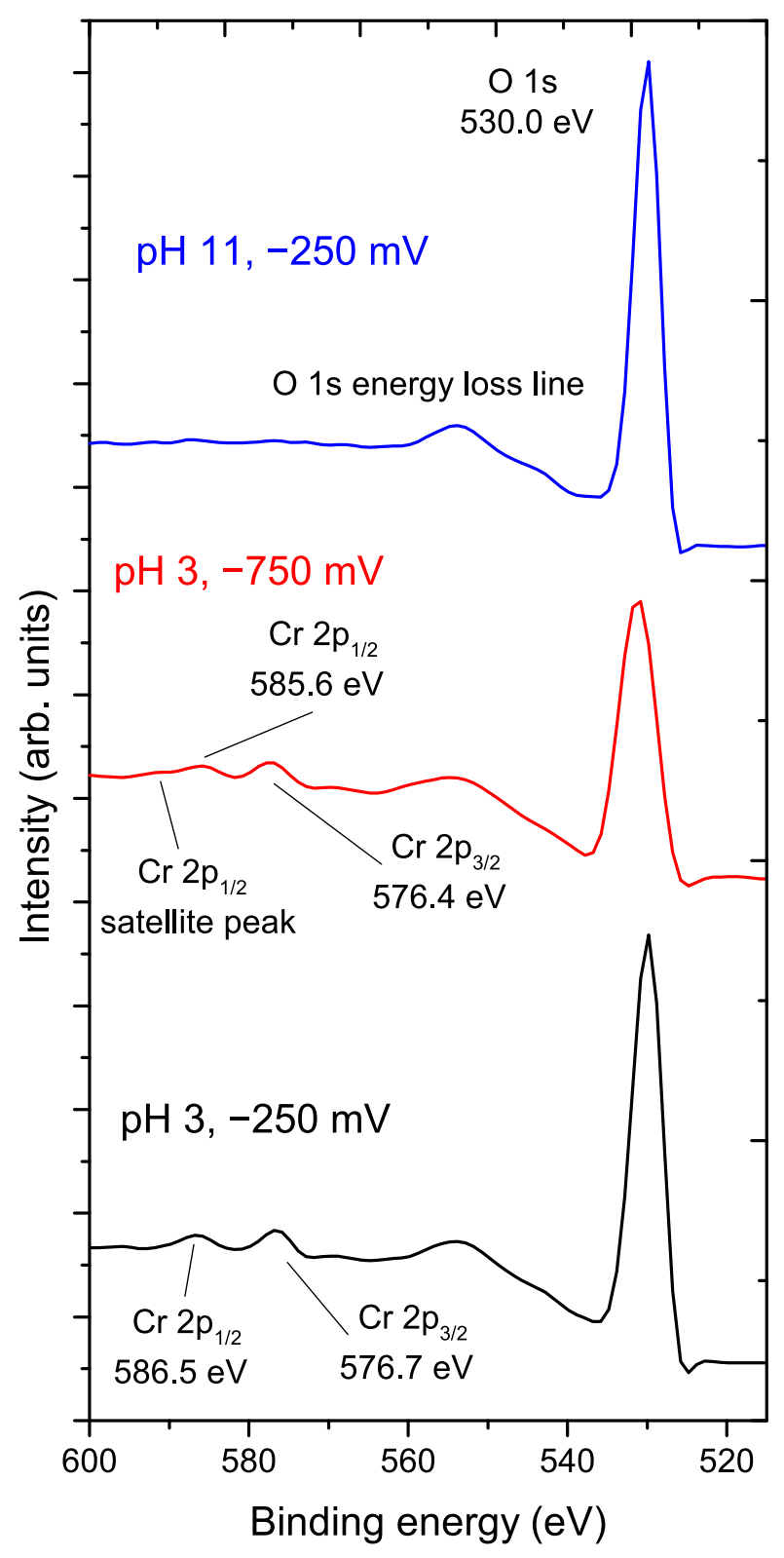

Figure 6 caption: XPS Cr $2 \mathrm{p}$ and $\mathrm{O} 1 \mathrm{~s}$ spectra. Peak positions shown are the result of single peak fitting. The $\mathrm{Cr} 2 \mathrm{p}_{3 / 2}$ and $2 \mathrm{p}_{1 / 2}$ peaks are clearly visible in the spectra for samples prepared at $\mathrm{pH} 3$; however, Cr $2 \mathrm{p}$ peaks do not appear in the $\mathrm{pH} 11$ spectra. This implies that any $\mathrm{Cr}$ on the surface is below the detection limit of the instrument. 


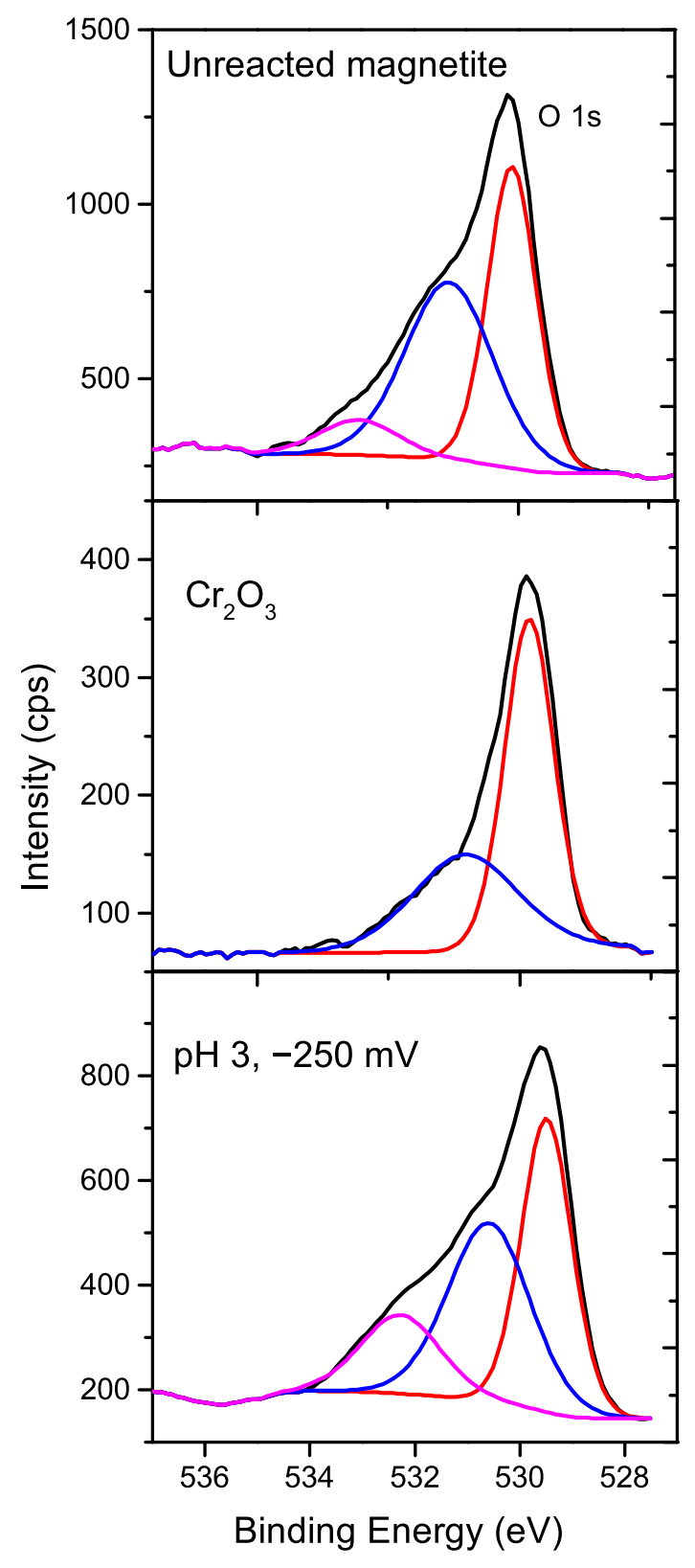

Figure 7 caption: Comparison of $\mathrm{O} 1 \mathrm{~s}$ core spectra for unreacted magnetite, $\mathrm{Cr}_{2} \mathrm{O}_{3}$, and the magnetite sample polarized for 20 minutes at $-250 \mathrm{mV}, \mathrm{pH} 3$. 


\section{Glass Slide with opening for scanner}

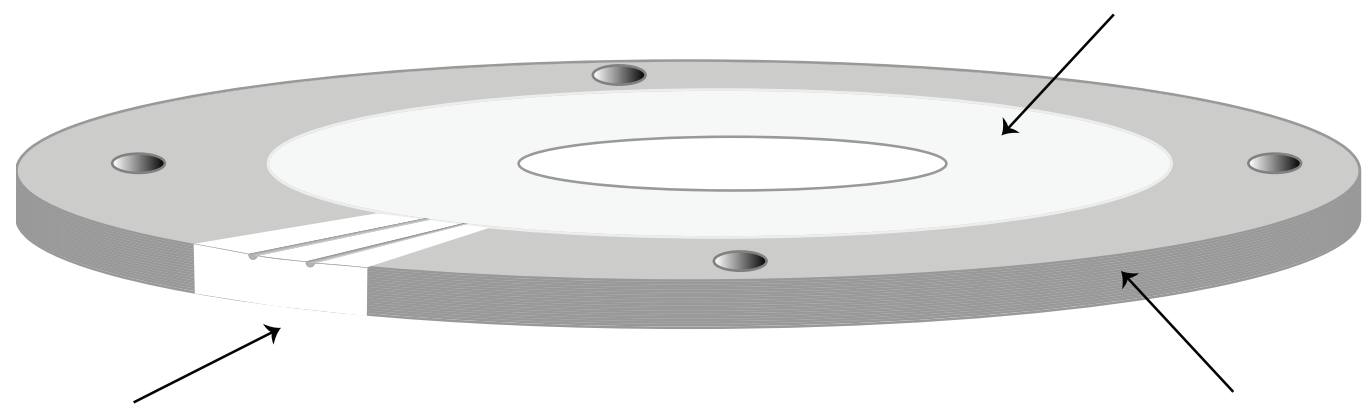

Teflon ${ }^{\circledR}$ counter and reference electrode holder

Stainless steel upper ring

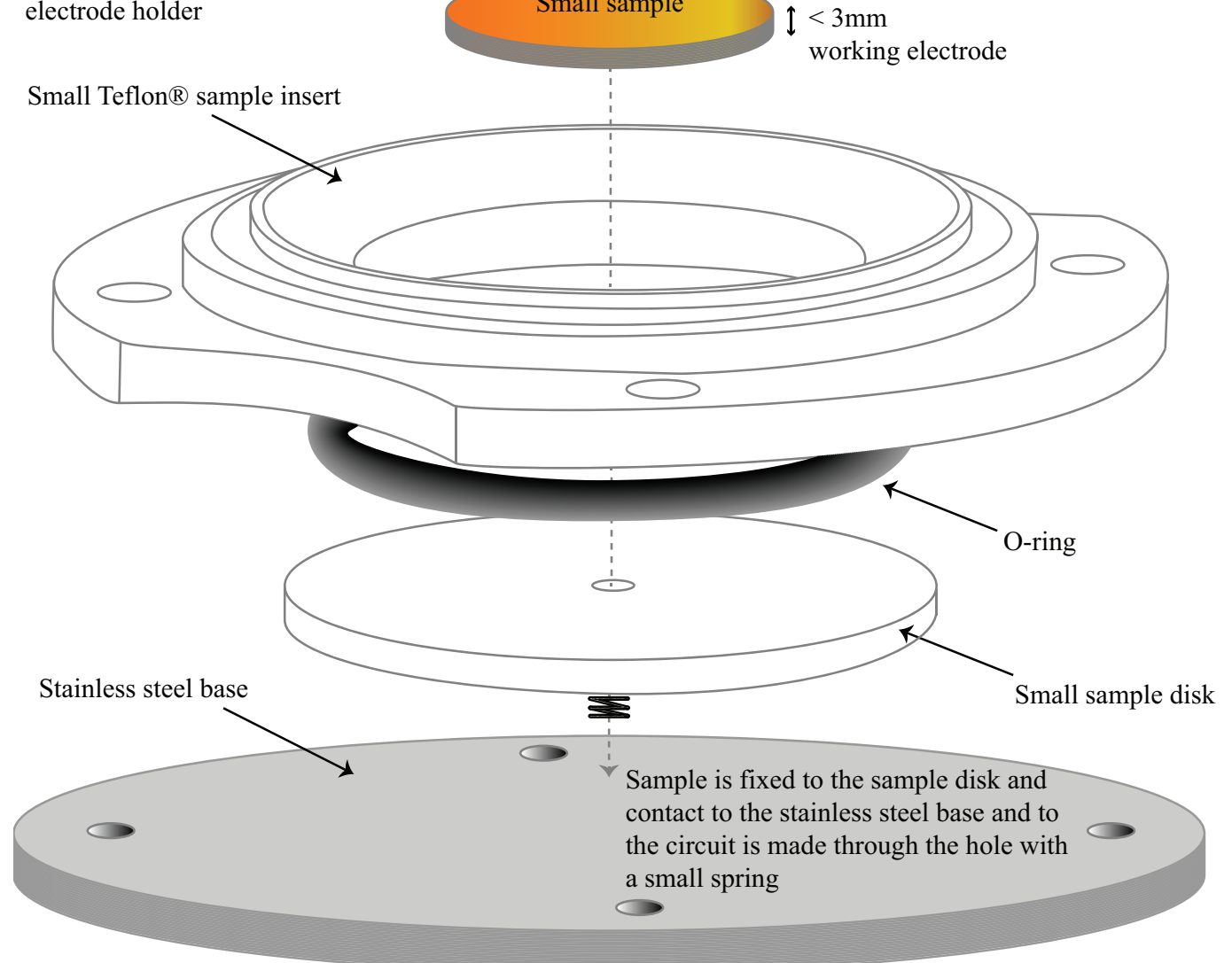

Appendix I - Simplified schematics of a second generation electrochemical cell. Figure modified from Bruker.

Figure A1 caption: Schematic of electrochemical AFM cell 

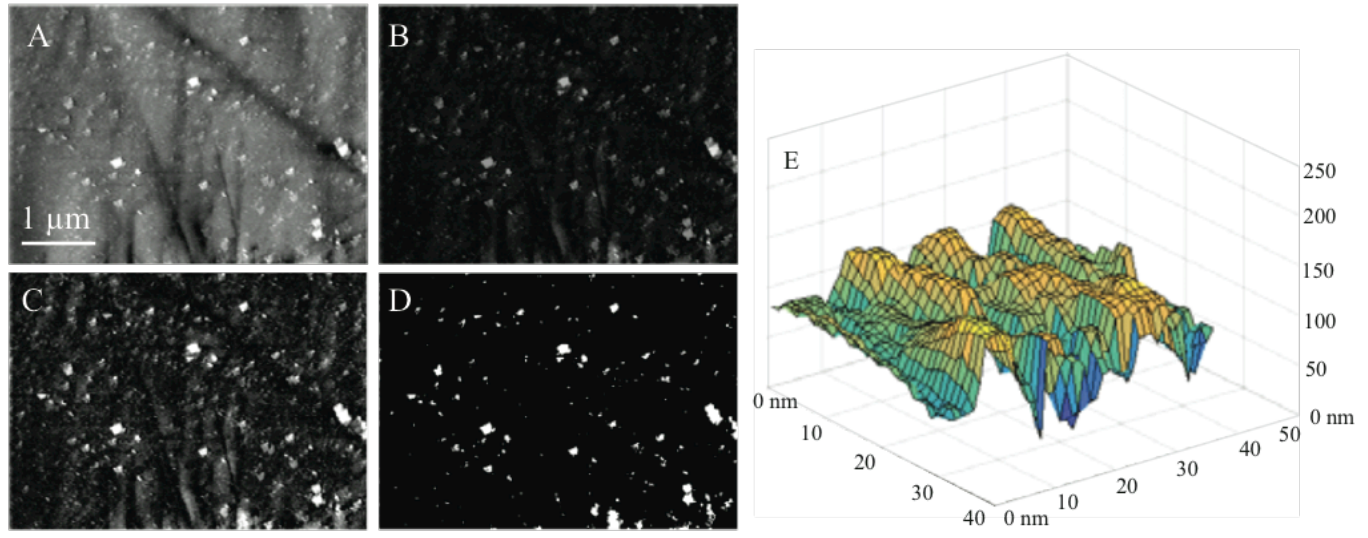

$400 \mathrm{~nm}^{10}$

Figure B1 caption: Detail of image analysis procedure for sorbate quantification. (A) Original grayscale image. (B) Original image minus script-generated background. (C) Enhanced contrast image. (D) Black and white binary image. (E) 3D background model. 


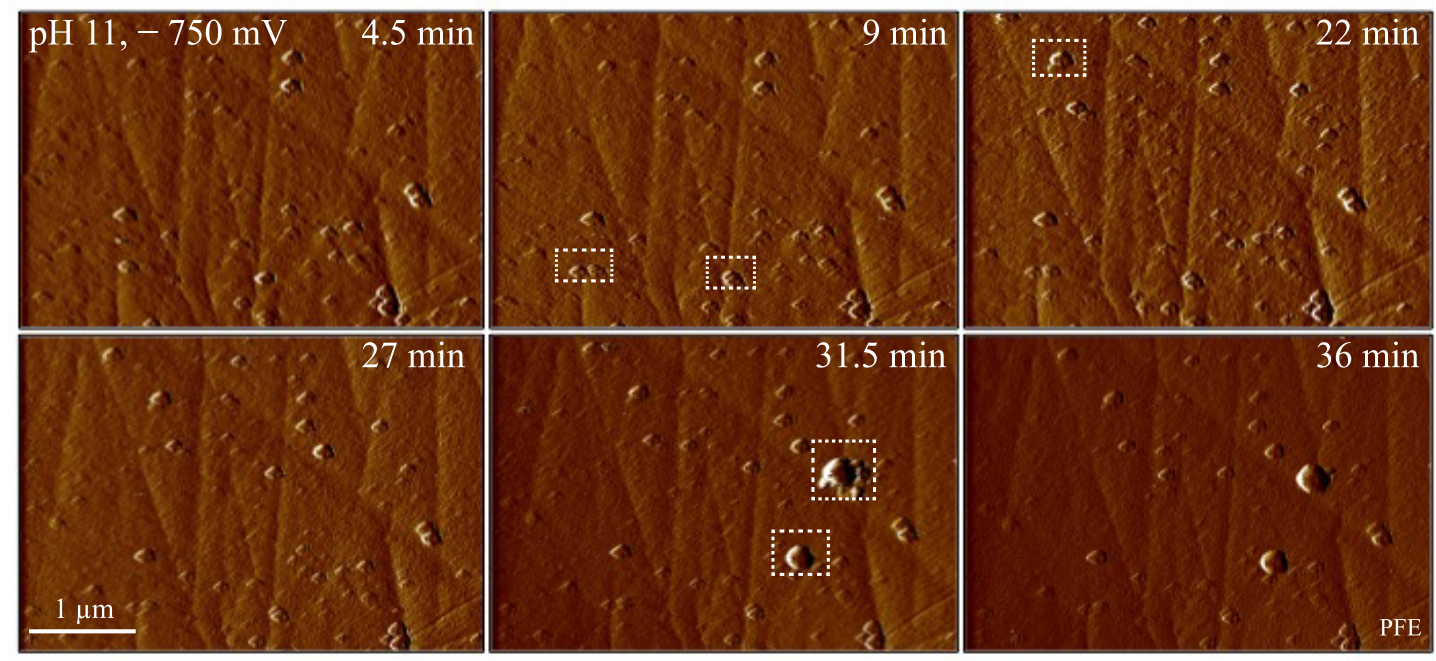

Figure $\mathrm{C} 1$ caption: Particle growth during polarization of the magnetite electrode at $-750 \mathrm{mV}$ as a function of time. Each image (which is peak force error data) was scanned in sequence. New growth features are marked by the white rectangles. 


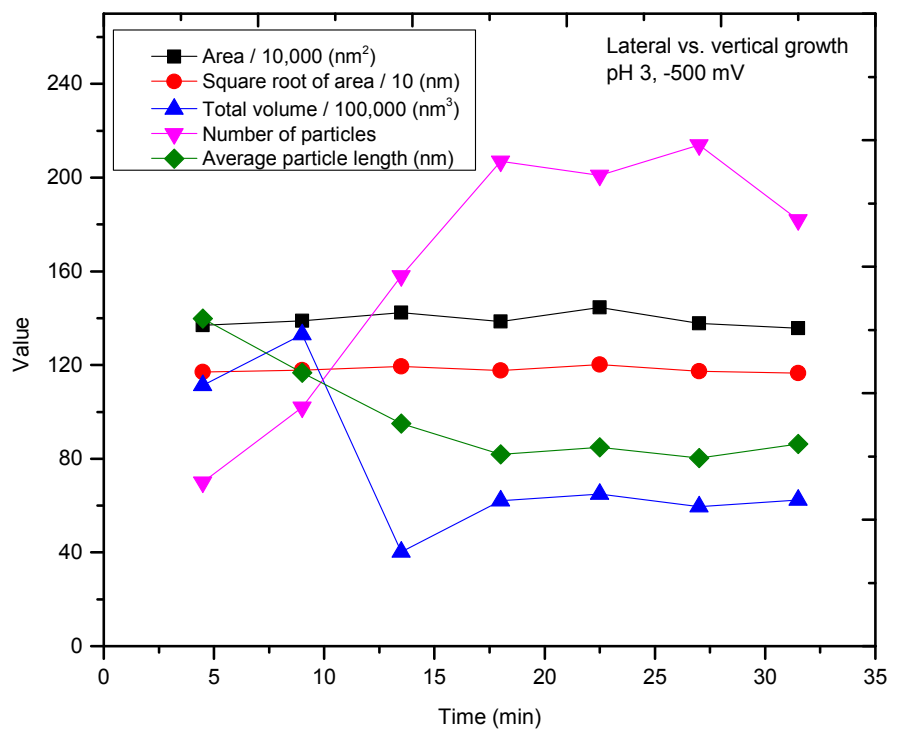

Figure $\mathrm{C} 2$ caption: Lateral vs. vertical growth at $\mathrm{pH} 3,-500 \mathrm{mV}$. The total volume decrease after ca. 35 minutes of reaction likely due to rapid initial precipitation followed by the dissolution of larger particles, shown here by decreasing average particle length (green line). 


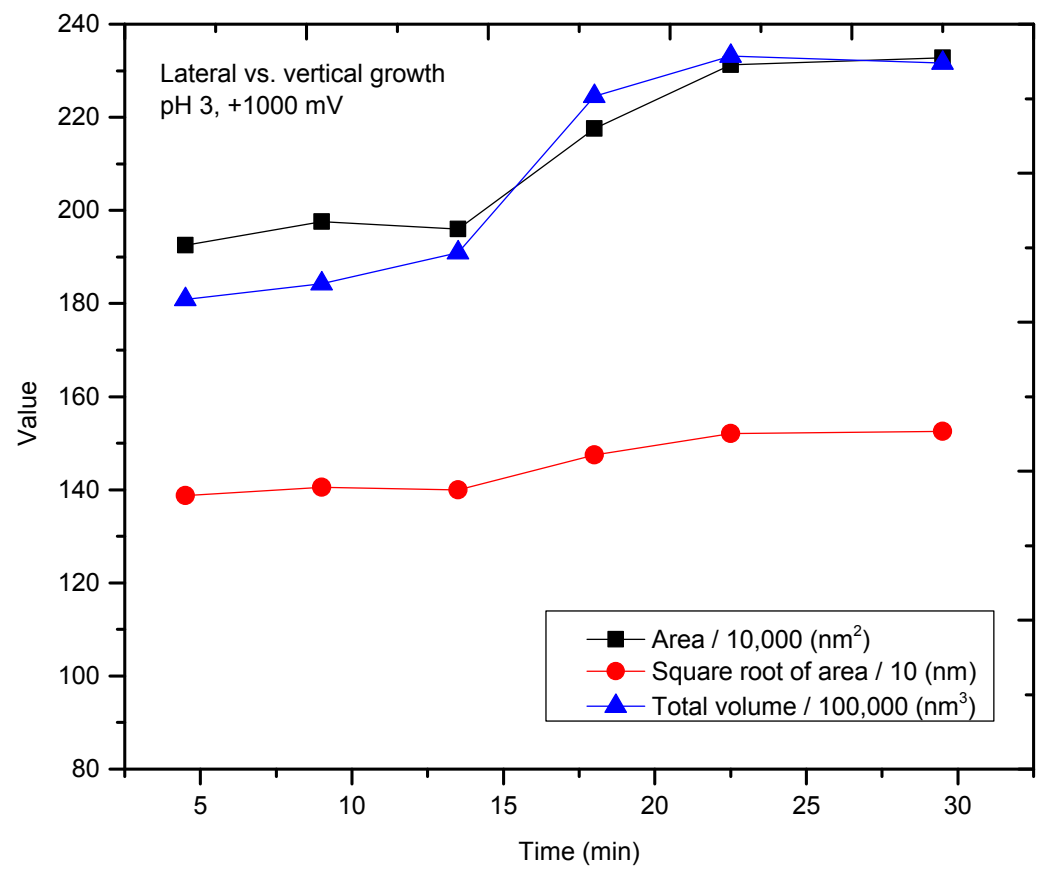

Figure $\mathrm{C} 3$ caption: Lateral vs. vertical growth at $\mathrm{pH} 3,+1000 \mathrm{mV}$. Growth at $\mathrm{pH} 3,+1000 \mathrm{mV}$ is primarily lateral, illustrated by the overlapping of the total volume and total area curves. 

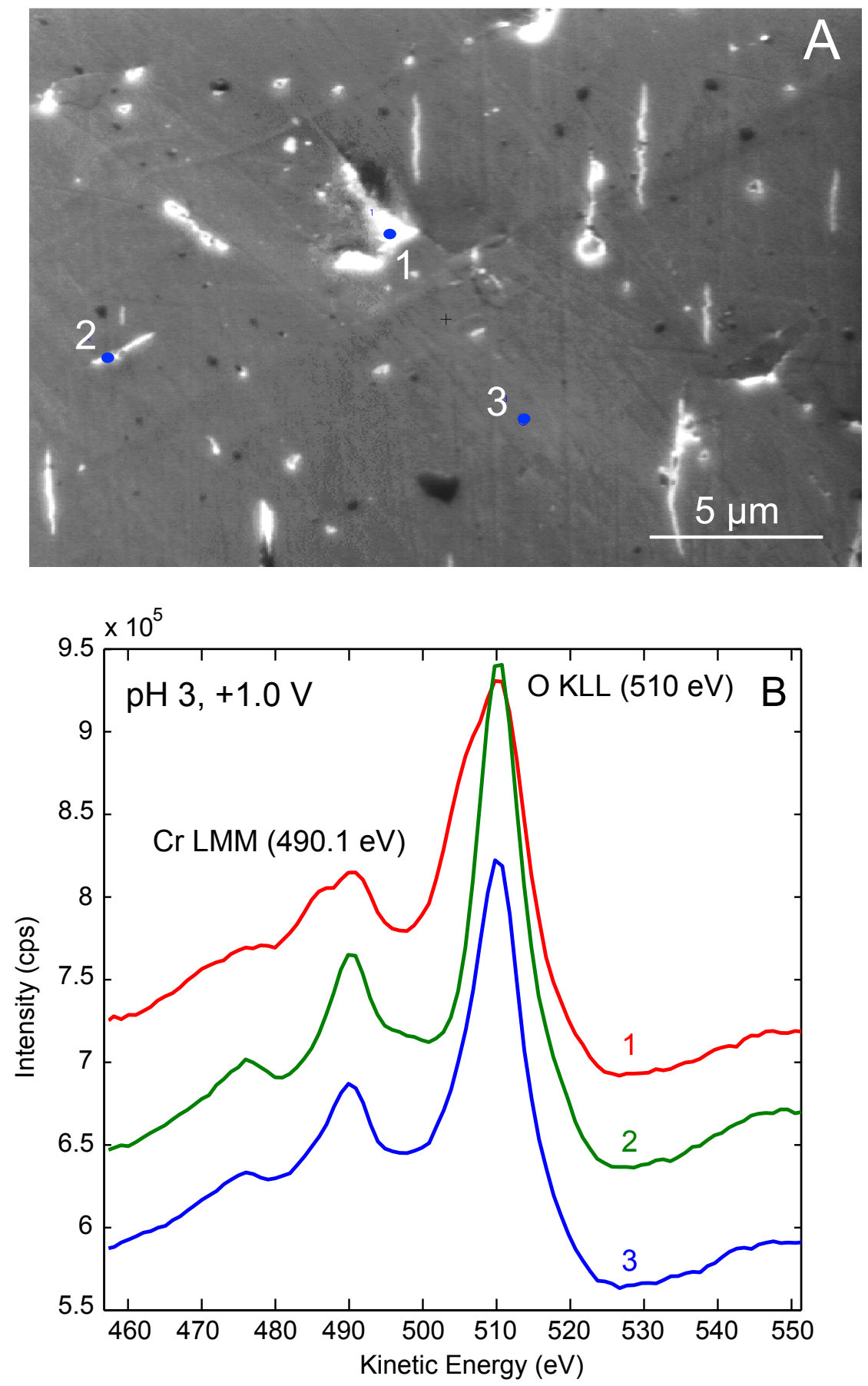

Figure D1 caption: SEM image (A) and undifferentiated Auger spectra (B) collected from $\mathrm{pH} 3,+1000 \mathrm{mV}$ magnetite surface. Three analysis spots are labeled in the SEM image, and their corresponding spectra are shown from 450 to $550 \mathrm{eV}$. The first spot measured was focused on a particle $\sim 1 \mu \mathrm{m}$ in diameter, the second spot on a flat, white feature, and the third spot on the "background" magnetite. The spectrum for point 1 has asymmetric Cr LMM and O KLL lines, which could indicate that multiple Cr phases are present, including $\mathrm{Cr}_{2} \mathrm{O}_{3}$. 


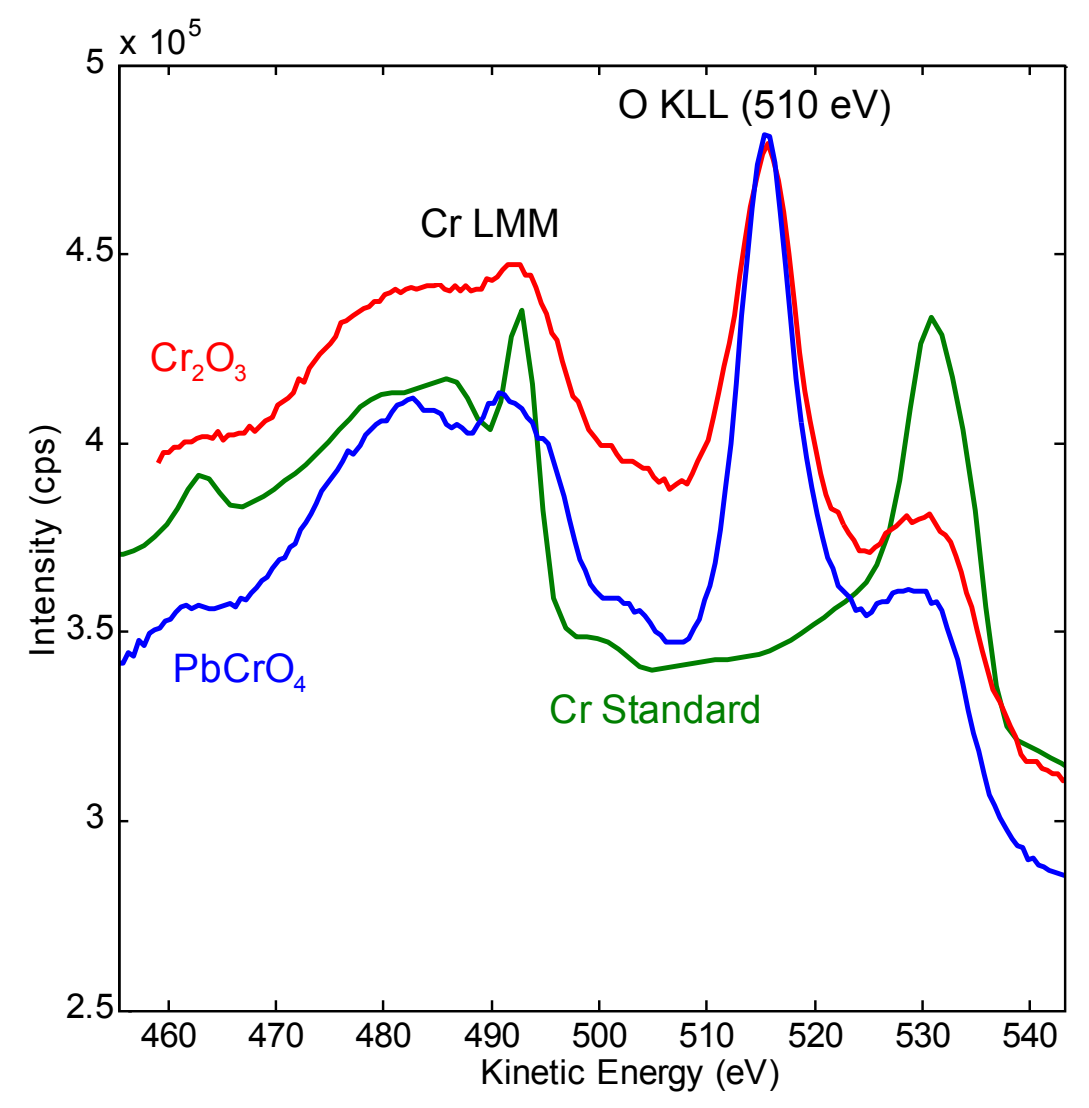

Figure D2 caption: Overlay of Auger spectra between 450 and $550 \mathrm{eV}$ for $\mathrm{Cr}$ in three oxidation states: $\mathrm{Cr}^{0}$ (Cr standard), $\mathrm{Cr}^{3+}\left(\mathrm{Cr}_{2} \mathrm{O}_{3}\right)$, and $\mathrm{Cr}^{6+}\left(\mathrm{PbCrO}_{4}\right)$. 

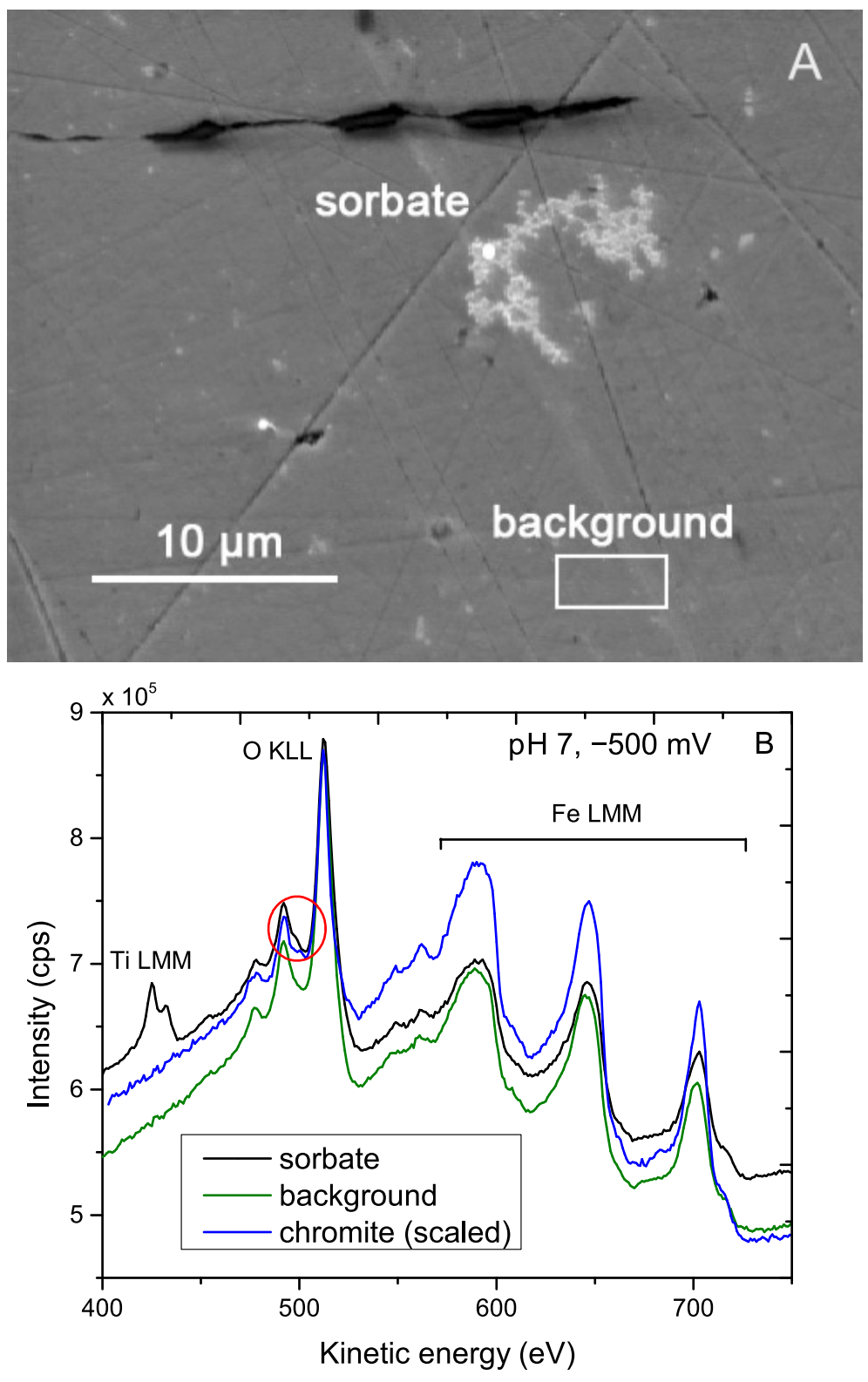

Figure D3 caption: SEM image (A) and AES spectra (B) of pH 7 surface. The white sorbate material labeled in the SEM image contains Ti as well as Cr. The Cr LMM peak at $\sim 490 \mathrm{eV}$ creates a shoulder on the higher kinetic energy side of the O KLL energy loss feature from the magnetite substrate (highlighted in the red circle). A chromite AES spectrum (scaled for clarity) is also shown. Spectra are shifted to the background O KLL peak to account for peak shifts due to charging. 

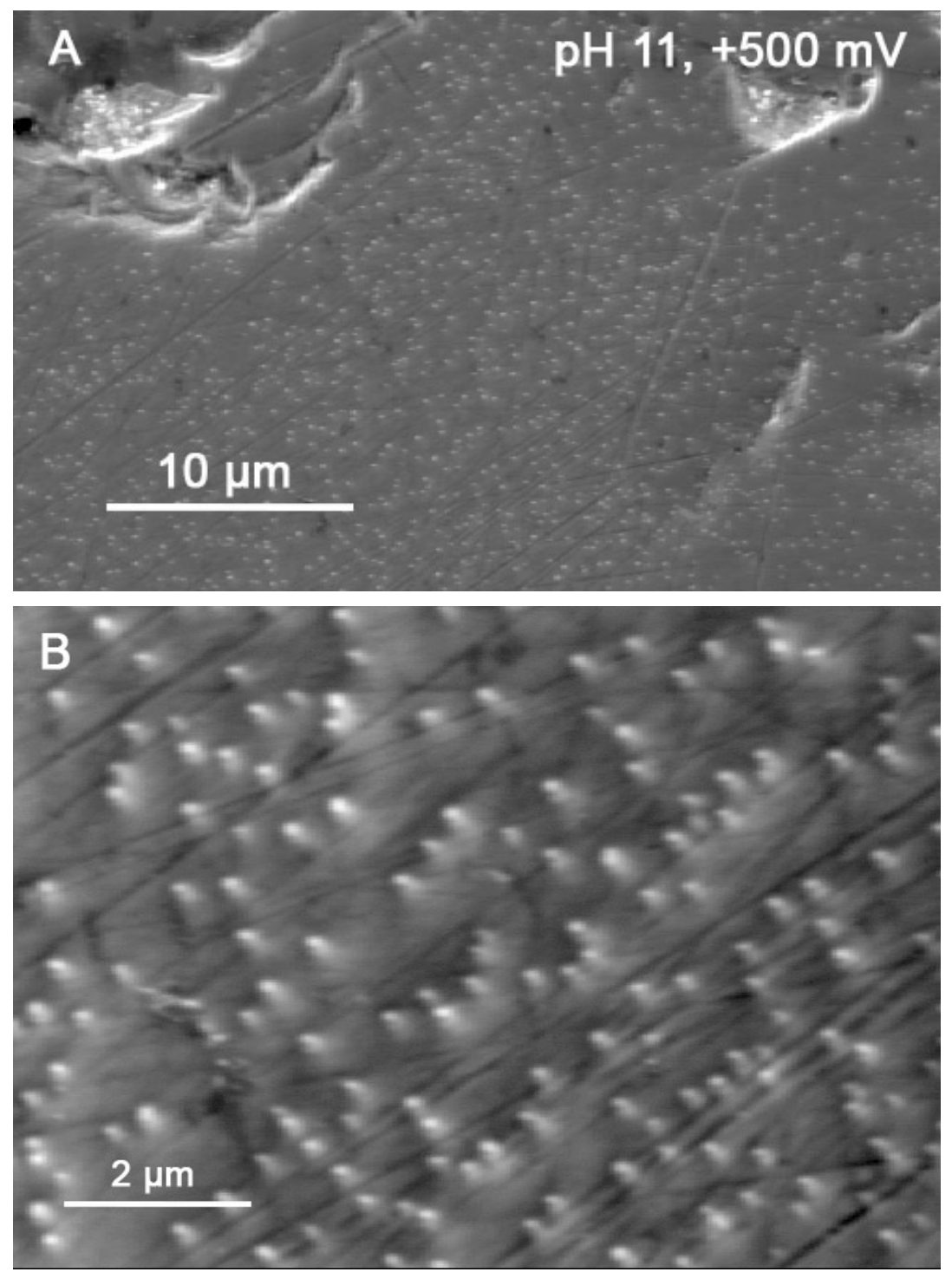

Figure D4 caption: Secondary electron images of particles on the surface of magnetite deposited at $\mathrm{pH} 11$, $+500 \mathrm{mV}$, taken using the Auger Nanoprobe. (A) Low resolution. (B) High resolution. 


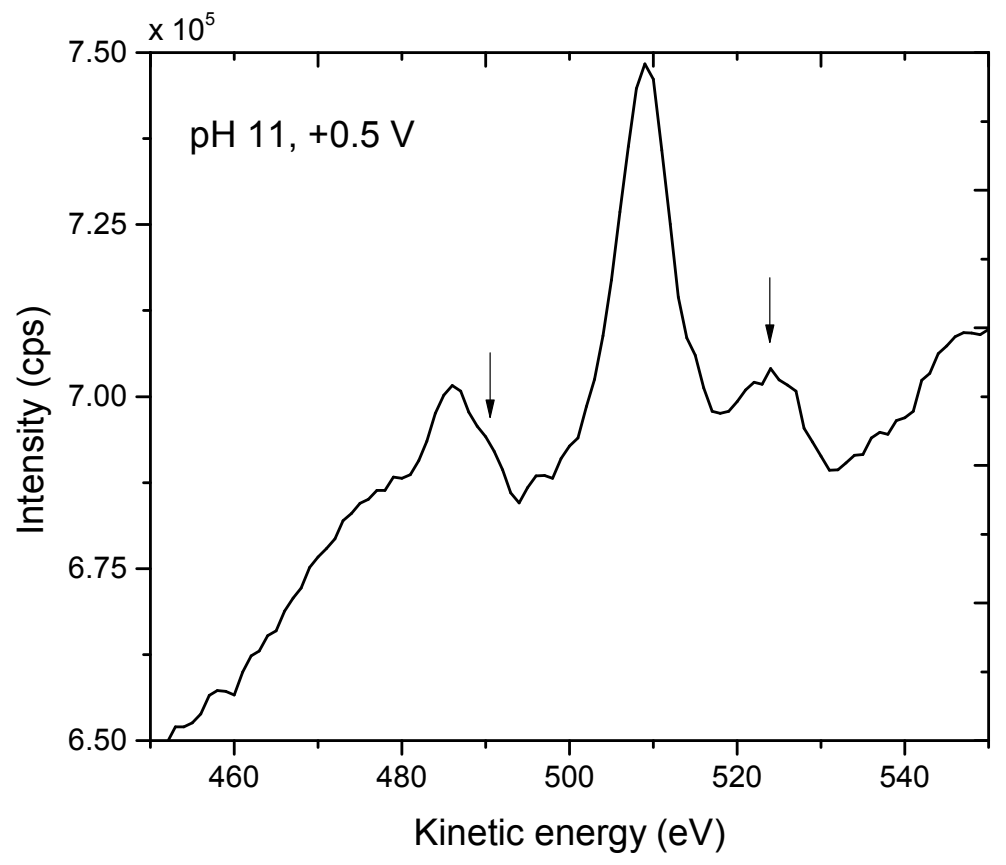

Figure D5 caption: AES spectrum for $\mathrm{pH} 11,+500 \mathrm{mV}$. Arrows indicate the presence of Cr peaks at ca. 490 and $530 \mathrm{eV}$, although the $\mathrm{Cr}$ oxidation state cannot be identified from this spectrum. It is possible that under oxidizing conditions, $\mathrm{Fe}_{2}\left(\mathrm{CrO}_{4}\right)_{3} \cdot 3\left(\mathrm{H}_{2} \mathrm{O}\right)$ can precipitate on the surface. 